\section{Lo sviluppo costruttivo della basilica di Ererouk (Armenia), secoli vi-x: una ri-lettura archeologica}

\section{Sequence in the construction of the Basilica of Ererouk in Armenia, $6^{\text {th }}-10^{\text {th }}$ centuries: a new archaeological interpretation}

Nadia Montevecchi

Dedalo s.a.s., Firenze (Italia)

Cristina Tonghini*

Università Ca' Foscari di Venezia (Italia)

Con una introduzione di

With an introduction by

Gaiané Casnati

Centro Studi e Documentazione della Cultura Armena, Milano (Italia)

\section{Riassunto}

Il presente contributo illustra i risultati di una campagna di indagini archeologiche sulla basilica di Ererouk, nella repubblica di Armenia, uno degli esempi più significativi dell'architettura religiosa della regione. L'analisi stratigrafica condotta nel 2005 permette di ricomporre la sequenza costruttiva dell'edificio in due principali Periodi, compresi probabilmente fra il vı ed il $\mathrm{x}$ secolo, e di rispondere ad alcune questioni che avevano innescato accesi dibattiti in letteratura, riguardanti ad esempio la natura delle coperture e la forma dei pilastri.

Parole chiave: Architettura religiosa armena. Prime basiliche armene. Basiliche orientali. Fase formativa architettura armena. Analisi stratigrafica.

\section{Abstract}

This paper illustrates the results of archaeological investigations carried out at the church of Ererouk, in the Republic of Armenia. This monument can be regarded as one of the most representative examples of religious architecture in the region. Stratigraphic analysis conducted in 2005 has allowed the establishment of a construction sequence for the building which is organized into two main periods and attributed to the $6^{\text {th }}$ to $10^{\text {th }}$ centuries. The data collected also contribute to several longdebated issues relating to early Armenian churches, including the system of roofing and the shape of the pillars employed.

Key words: Armenian religious architecture. Early Armenian basilica. Oriental basilica. The formation of Armenian architecture. Stratigraphic analysis.

\section{INTRODUZIONE' (GC)}

La basilica di Ererouk si trova a nord ovest della capitale dell'Armenia, Erevan, lungo il confine che separa l'Armenia dalla Turchia, poco distante dalla rinomata capitale medievale armena di Ani. Questa particolare ubicazione l'ha resa pressoché inaccessibile agli studiosi per un lungo periodo, ma le caratteristiche architettoniche della basilica, uniche nel panorama dell'edilizia religiosa medievale armena, hanno contribuito ad attirare e mantenere vivo l'interesse della comunità scientifica per questo edificio.

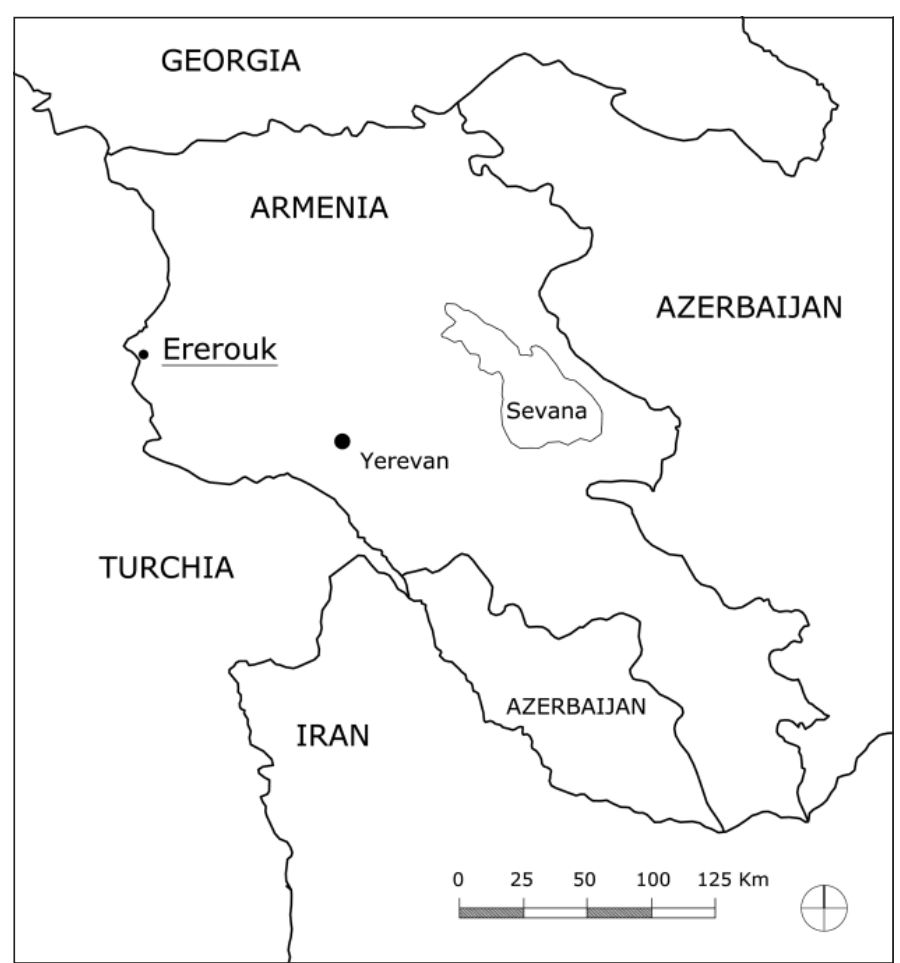

Fig. 1. Localizzazione del sito di Ererouk, Armenia

A seguito dei gravi danni strutturali riportati dalla basilica con il forte terremoto che ha colpito il nord dell'Armenia nel dicembre 1988, il governo armeno andò a richiedere l'aiuto della comunità internazionale in termini di consulenza scientifica e sostegno economico per potere procedere al restauro dell'edificio.

Dopo due prime promettenti missioni italiane di carattere prettamente conoscitivo organizzate nel 1989, il contributo italiano subì una battuta di arresto. Nel 1995 intervenne il World Monuments Fund con un progetto di restauro, a firma dell'arch. Gionata Rizzi, che però non venne

${ }^{1}$ L'analisi archeologica condotta ed i risultati qui presentati sono frutto di un lavoro comune di N. Montevecchi e C. Tonghini. Per quel che riguarda il testo, C. Tonghini ha curato la stesura del Periodo I, N. Montevecchi la stesura del Periodo II; il resto del testo è a cura di entrambi gli autori. Il rilievo qui presentato (Figg. 2, $4,8,10,14,19)$ costituisce una revisione e messa a punto di versioni precedenti, ed è stato curato dall'arch. Hilde Romanazzi. La caratterizzazione archeologica delle tavole (Figg. 4, 8, 10, 14, 19) è stata curata da N. Montevecchi. 
approvato dal Comitato per la Conservazione dei Monumenti. Nel 1996 l'arch. Vitali Guevorkian realizzò un intervento di emergenza per la messa in sicurezza dei muri pericolanti sui lati ovest, nord-ovest e sud-est della basilica; questa operazione, configuratosi sostanzialmente come una sorta di puntellamento dei muri con traversine ferroviarie poste in opera su robuste fondazioni in cemento armato, si rivelò dannosa, oltre che antiestetica, e mise in evidenza l'urgenza di intervenire con un progetto più adeguato.

Il governo armeno si rivolse dunque al Centro Studi e Documentazione della Cultura Armena (CSDCA) che avviò una nuova stagione di interventi, coordinati da chi scri$\mathrm{ve}^{2}$, che hanno portato a fermare il rischio immediato di crollo ed a promuovere lo studio scientifico della basilica.

A partire dal 2002 vennero realizzati una serie di interventi che andarono a risolvere le emergenze più pressanti anche grazie ad un programma di formazione richiesto dalI'UNESCO e coordinato dal CSDCA. Infine, nel 2004, ha preso il via un programma di indagini conoscitive che comprendeva uno studio strutturale $e^{3}$ ed analisi geologiche, geotecniche e sismiche. In quest'ambito si sono collocati anche una serie di studi specialistici delle emergenze architettoniche affidati a Nadia Montevecchi e Cristina Tonghini, i cui risultati sono qui presentati; a Jean-Claude Bessac (CNRS, Montpellier III, UMR 5140, Lattes $)^{4}$; a Christina Maranci (Università del Wisconsin-Milwaukee). Un nuovo programma di indagini strutturali è stato avviato a partire dal 2005 da Vincenzo Petrini (Dipartimento di Ingegneria Strutturale del Politecnico di Milano).

Molto resta ancora da fare per completare lo studio scientifico di questo importante monumento e per realizzare un progetto integrato di conservazione e valorizzazione della basilica e del suo contesto. A questo scopo il CSDCA ha stipulato nel 2010 una convenzione di collaborazione con il Laboratoire d'Archéologie Médiévale et Moderne en Méditerranée LA3M (ex LAMM) del CNRS Université d'Aix-Marseille che dal 2009 ha attivato un progetto di ricerca storico-archeologica sul sito di Ererouk.

\section{LE INDAGINI ARCHEOLOGICHE DEL 2005 (NM E CT)}

\section{Premessa}

Il percorso che ci ha portato ad occuparci di una struttura in Armenia parte da un ampio programma di riflessione e

\footnotetext{
${ }^{2}$ Questo nuovo programma ha beneficiato del supporto del Ministero degli Affari Esteri nell'ambito del Progetto Pilota «Salvaguardia e valorizzazione del patrimonio architettonico: tecnologie innovative e tecniche tradizionali», nella Repubblica d'Armenia.

${ }^{3}$ A questo studio partecipa anche l'esperto locale ing. Paruyr Zadoyan.

4 I risultati degli studi condotti da J.-Cl. Bessac sono confluiti in due pubblicazioni: Bessac 2011 e Bessac, c.s.
}

ricerca sulla fortificazione nel Vicino e Medio Oriente, e nasce dall'esigenza di acquisire alcune conoscenze di base sulle pratiche costruttive di una regione che sembra costituire un elemento cardine nella storia dell'evoluzione dell'architettura dell'area considerata, co-erede di un sapere costruttivo di tradizione 'classica' che qui sembra essersi mantenuto e trasmesso senza apparente soluzione di continuità per un ampio arco cronologico.

Proprio le ricerche sulle origini della fortificazione nell'area siriana, avviate con un progetto di indagini sul campo incentrate sul castello di Shayzar nel 2002, ci avevano portato ad un primo confronto con le maestranze armene: a quanto ci riferiscono le fonti scritte, queste avevano giocato un ruolo di primo piano nella realizzazione di una prima rete fortificata nel Mediterraneo orientale già a partire dal X secolo (Voisin 2004); questo ruolo è ben attestato nelle celebrate porte di al-Qahira, datate con precisione fra il 1087 ed il 1092, ricordate come uno degli esempi più antichi di fortificazione nel mondo islamico ed attribuite a maestranze armene (Creswell 1952; Yovitchitch 1991, pp. 109-114). L'acquisizione di alcune conoscenze di base sulle pratiche costruttive armene sembrava dunque un passaggio ineludibile per un coerente approfondimento di alcune linee di ricerca. La solida collaborazione avviata sempre sul cantiere di Shayzar con il Centro Studi e Documentazione della Cultura Armena (CSDCA), ed in particolare con l'arch. Casnati, ha presto fornito l'occasione di dare concretezza a questa parte del programma e ci ha consentito di prendere parte al progetto incentrato sulla basilica di Ererouk con una prima stagione di indagini archeologiche sul campo nell'agosto 2005.

Lo scopo di questa prima campagna di indagini era quello di ricomporre la sequenza costruttiva dell'edificio con l'impiego delle metodologie proprie dell'analisi stratigrafica, e tentare attraverso i dati raccolti di rispondere ad alcune questioni che avevano innescato accesi dibattiti in letteratura, riguardanti ad esempio la natura delle coperture (a volte, a capriate) e la forma dei pilastri (a $\mathrm{T}$, a croce). Le nostre indagini si collocavano nell'ambito di un più ampio progetto che prevedeva approfondimenti specifici condotti da altri specialisti.

Una sintesi dei dati raccolti era confluita in una prima relazione preliminare redatta all'indomani della conclusione della campagna, con una prima elaborazione interpretativa ${ }^{5}$. Il doveroso impegno a rendere davvero fruibili quei

\footnotetext{
${ }^{5}$ N. Montevecchi e C. Tonghini, Basilica di Ererouk: relazione preliminare sulle indagini archeologiche, settembre 2005; redatta in italiano, e tradotta in francese da C. Tavernari per metterla a disposizione degli studiosi che sarebbero intervenuti nella campagna prevista per l'autunno, J.-Cl. Bessac e Ch. Maranci. La relazione era accompagna da elaborazioni grafiche che comprendevano una
} 
dati, pensando soprattutto agli studiosi che dopo di noi si sarebbero occupati della basilica, ci ha spinto, pur a distanza di anni, a riprendere in mano questo lavoro e a rielaborare più compiutamente l'intera documentazione raccolta. La scelta dell'italiano come lingua per questa pubblicazione finale vuole soprattutto rendere omaggio alla assai prolifica stagione di studi che ha caratterizzato gli anni ' 60 e ' 70 , testimoniata nelle numerose pubblicazioni.

\section{La lettura stratigrafica: finalità e strategie}

La prima campagna di indagini archeologiche condotta da chi scrive sulla basilica di Ererouk nell'agosto 2005 era finalizzata alla identificazione delle principali fasi costruttive che avevano interessato l'edificio attraverso l'applicazione delle metodologie proprie dell'analisi stratigrafica degli alzati. Oltre alla ricomposizione della sequenza costruttiva, le indagini erano anche indirizzate alla individuazione di elementi che permettessero di comprendere alcuni aspetti costruttivi della struttura, in particolare quelli relativi alla tipologia delle coperture ${ }^{6}$. Questo aspetto era infatti stato per decenni oggetto di un acceso dibattito che aveva trovato ampio spazio nella letteratura specialistica dedicata all'edificio.

Il programma di lavoro sul campo era stato concepito come il primo di una serie di sopralluoghi, poi mai davvero effettuati per intercorse difficoltà organizzative riguardanti chi scrive. Il lavoro sul campo si configurava inoltre come parte di un progetto articolato nell'ambito del quale era prospettato l'intervento di altri specialisti con diverse e specifiche competenze, come quello di J.-Cl. Bessac e di Ch. Maranci, già previsto per lo stesso autunno del 2005.

Nell'impostare il nostro lavoro, dunque, abbiamo tenuto conto del fatto che aspetti specifici, riguardanti ad esempio la definizione e l'analisi tipologica del materiale impiegato, o l'organizzazione del cantiere, avrebbero certamente trovato uno spazio più adeguato nello studio di uno specialista come J.-Cl. Bessac ${ }^{7}$. Al tempo stesso, in considerazione della nostra formazione prettamente archeologica da una parte, e del programmato intervento di uno speciali-

prima suddivisione in fasi, e da tutta la documentazione grafica definita in cantiere, con la registrazione delle interfacce fra le US riportate su fotografia; non comprendeva invece una descrizione delle US. L'intera documentazione è stata poi messa a disposizione degli studiosi del Laboratoire d'Archéologie Médiévale Mediterraneénne (CNRS e Université de Provence) che nel 2009 hanno avviato un nuovo progetto di ricerca sotto la direzione di Patrick Donabedian.

${ }^{6}$ Per un inquadramento del problema, si vedano ad esempio Alpago-Novello, 1977, pp. 18-22; Paboudjin 1977, pp. 4, 8-11; Gandolfo 1982, pp. 67-68.

${ }^{7} \mathrm{~J}$.-Cl. Bessac ci ha gentilmente fornito il rapporto relativo alla campagna da lui condotta nel 2005; nel gennaio 2012 ci ha infine fornito il dattiloscritto depositato per la stampa, Bessac c.s. In questa nostra pubblicazioni facciamo dunque riferimento a quest'ultimo elaborato per questioni specifiche, senza tuttavia anticiparne i contenuti o discuterne gli spunti interpretativi. sta di storia dell'architettura armena come Ch. Maranci dall'altra, non abbiamo che marginalmente contemplato gli aspetti stilistico-formali e decorativi della struttura ${ }^{8}$.

Il lavoro sul campo si è dunque concentrato, in quella prima stagione, sull'analisi stratigrafica di base. Nel corso di quella prima campagna, la mancata disponibilità di un rilievo aggiornato, metricamente corretto ma che comprendesse anche una descrizione fotogrammetrica degli alzati, meglio compatibile con la complessità della documentazione che deriva da una lettura stratigrafica di quanto lo possano essere i disegni al tratto, ci ha indotto a registrare l'analisi su una serie di fotografie; per la stesura della relazione preliminare, la lettura e la relativa suddivisione in fasi è stata riportata sul disegno al tratto allora disponibile. Per la pubblicazione finale dei dati qui presentata, si è invece utilizzato un nuovo rilievo, messo a punto successivamente, sempre al tratto?.

$\mathrm{Ci}$ preme sottolineare che nelle tavole è stata fedelmente riportata la lettura effettuata sul campo nel 2005, senza introdurre sostanziali modifiche che non partissero da un riesame autoptico dell'evidenza, inclusa la numerazione delle US (Figg. 4, 8, 10, 14, 19) ${ }^{10}$.

Non è stato possibile condurre una analisi sistematica delle malte di allettamento, anche perché molte porzioni murarie risultavano insondabili per la presenza di invasive stuccature di malta cementizia stesa durante i recenti restauri. Una prima limitata campionatura ha riguardato alcuni aspetti specifici, ma ancora non è stato possibile procedere ad una analisi in laboratorio dei campioni, e ci siamo limitate ad un primo esame macroscopico dei prelievi effettuati.

\section{RISULTATI ${ }^{11}$}

In questa fase iniziale dello studio sono stati individuate cinque diverse Fasi costruttive riferibili a due diversi Periodi (Periodo I e II), seguite da un lungo periodo di abbandono (Periodo III) e da varie fasi di restauro (Periodo IV).

\footnotetext{
${ }^{8} \mathrm{G}$. Casnati ci ha fornito il breve rapporto redatto da Ch. Maranci in seguito al suo sopralluogo, cui qui facciamo riferimento come Maranci 2005.

${ }^{9}$ Il rilievo qui utilizzato è stato realizzato ed elaborato dall'architetto Hilde Romanazzi.

${ }^{10}$ In alcuni casi erano stati definiti sul campo i soli contorni di una serie di US; ove non è stato possibile risalire ad una descrizione di queste US e dei loro rapporti, ma verificatane la sostanziale congruenza con le ipotesi qui delineate, ci è sembrato più corretto riportare questi contorni sulle tavole senza tuttavia procedere ad una numerazione 'a tavolino'.

${ }^{11}$ Allo scopo di rendere più leggibile il testo, ed in considerazione del fatto che, come anticipato nel paragrafo La lettura stratigrafica: finalità e strategie, le tavole riportano solamente la numerazione delle US definita in cantiere, nella discussione sono generalmente citati solo i numeri di US essenziali alla comprensione dei vari passaggi, e non l'intero elenco.
} 


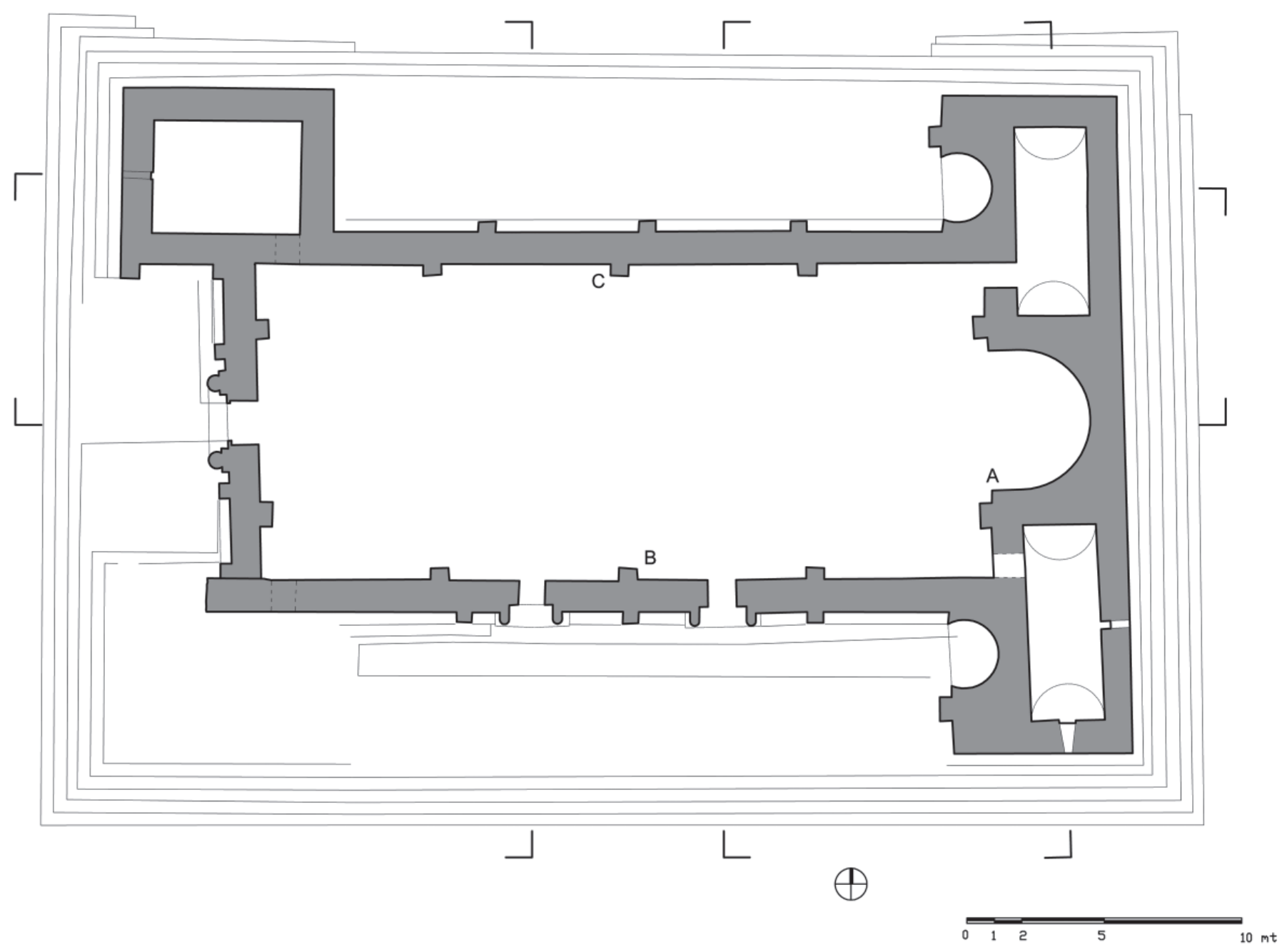

Fig. 2. Pianta generale della basilica, con indicazione dei sondaggi esplorativi (rilievo H. Romanazzi)

Le Fasi pertinenti la realizzazione della chiesa (Fasi 15. Attività 1-26) sono state inquadrate in due distinti Periodi costruttivi (Figg. 4, 8, 10, 14, 19). Con il Periodo I (Fasi 1-3, Attività 1-21) viene realizzata una prima chiesa corrispondente in planimetria alla chiesa attuale (Fig. 2); il progetto per la sua copertura viene impostato ma riteniamo che i lavori si interrompano prima della sua completa realizzazione. Nel Periodo II (Fasi 4-5, Attività 22-26) vengono apportate delle modifiche ai volumi della chiesa originariamente progettata, con l'obliterazione dei portici nord e sud ed una riprogettazione di quello ovest, e vengono finalmente realizzate le coperture. In considerazione delle tecniche e della tipologia di materiale impiegati è assai probabile che i due Periodi siano abbastanza vicini dal punto di vista cronologico.

Il Periodo III individua un lungo periodo di abbandono, cui fa seguito l'avvio della più recente stagione di studi e degli interventi di restauro di recente realizzazione (Periodo IV).

\section{Periodo I}

L'evidenza esaminata indica che già a partire da questo primo Periodo viene progettata e realizzata una chiesa che sviluppa in pianta le componenti che caratterizzano anche l'edificio attuale (Fig. 2): una basilica a tre navate, orientata est-ovest e collocata su uno stilobate a gradoni, con un corpo absidale corredato di due vani laterali che aggettano sui lati nord e sud, e due corpi parimenti aggettanti che inquadrano la facciata ovest; $i$ corpi in aggetto definiscono sui fronti sud e nord due spazi esterni, provvisti di portici, entrambi completati da un'abside sul lato est. Anche lo spazio delimitato dalle due torri, sulla facciata ovest, era corredato da un porticato con arcate.

Gli interventi successivi non andranno a modificare questo primitivo impianto se non marginalmente, con trasformazioni legate essenzialmente a quella che riteniamo configurarsi come una riduzione dei volumi in altezza (Periodo II, si veda infra).

Nel Periodo I vengono gettate le fondazioni e realizza- 


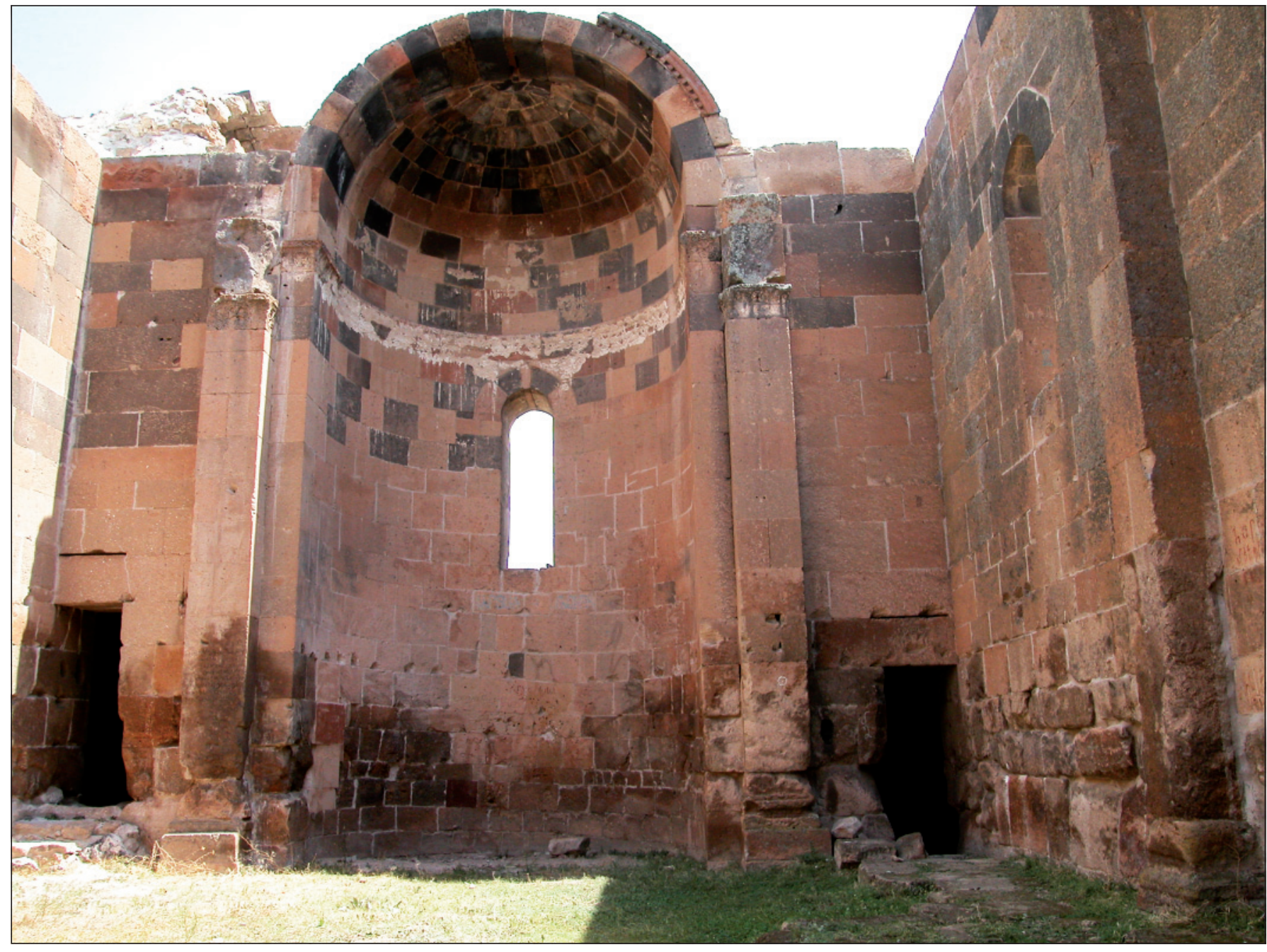

Fig. 3. La parete absidale interna, da ovest (Foto N. Montevecchi)

te le strutture dell'alzato almeno fino al livello delle coperture. Le modifiche successive ed il crollo delle porzioni sommitali non consentono di stabilire con certezza se la fabbrica di questo Periodo sia stata portata a compimento con la realizzazione delle coperture; tuttavia, l'assenza di evidenze chiaramente riconducibili a crolli e l'andamento orizzontale delle interfacce fra il Periodo I ed il Periodo II rendono assai verosimile la possibilità che la chiesa del Periodo I non sia mai stata completata.

Il processo costruttivo sembra subire interruzioni, anche di una certa consistenza: alcune sono certamente riconducibili all'emergenza di problemi strutturali, altre sembrano legate all'organizzazione logistica del cantiere (messa in volta degli ambienti, avvicendamento delle maestranze e delle stagioni, approvvigionamento del materiale) oppure potrebbero essere connesse ad eventi storici che ancora necessitano di una puntuale messa a fuoco.
Fase 1 (Figg. 4, 19, colore viola)

Attività 1: costruzione della fondazione (Fig. 5);

Attività 2: costruzione dell'alzato: abside e ambienti interni laterali (Figg. 3-4, 19);

Attività 3: avvio della costruzione dei perimetrali sud e nord (un solo filare visibile) (Figg. 5-6);

Attività 4: cedimento fondale nell'abside e negli ambienti laterali (Figg. 3-4);

Attività 5: interruzione dei lavori (Figg. 3-4).

In questa fase viene avviata la costruzione di un edificio che sviluppa in pianta gran parte delle componenti dell'edificio attualmente conservato (Fig. 2).

La struttura delle fondazioni è stata esaminata in tre punti della fabbrica attraverso l'apertura di tre saggi di limitate dimensioni (localizzati in pianta come saggi A, B, C, Fig. 2). Il saggio A è stato collocato nell'angolo 


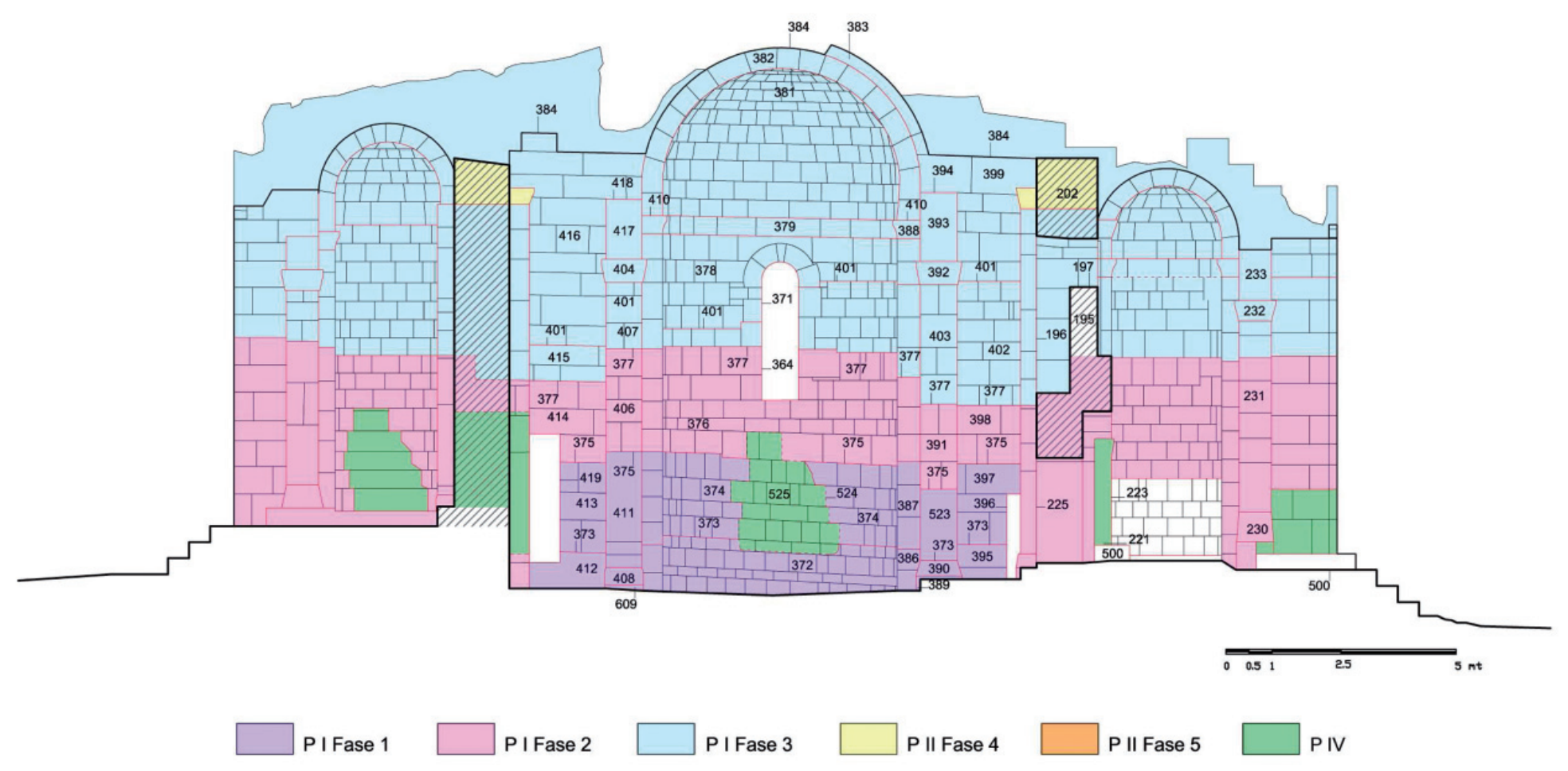

Fig. 4. Prospetto est interno: lettura stratigrafica (rilievo H. Romanazzi, caratterizzazione archeologica N. Montevecchi)

meridionale dell'abside, i saggi $\mathrm{B}$ e $\mathrm{C}$ all'interno delle pareti perimetrali meridionale e settentrionale in corrispondenza delle paraste centrali (Figg. 2, 5). La porzione esaminata mostra che le fondazioni dell'edificio poggiano sul banco roccioso, più alto in corrispondenza del fronte nord; sono costruite con pietre prevalentemente spaccate, in alcuni casi sommariamente lavorate, ed allettate con malta terrosa.

In corrispondenza del saggio B (Figg. 2, 5) è stato rinvenuto uno strato di terra dello spessore di qualche

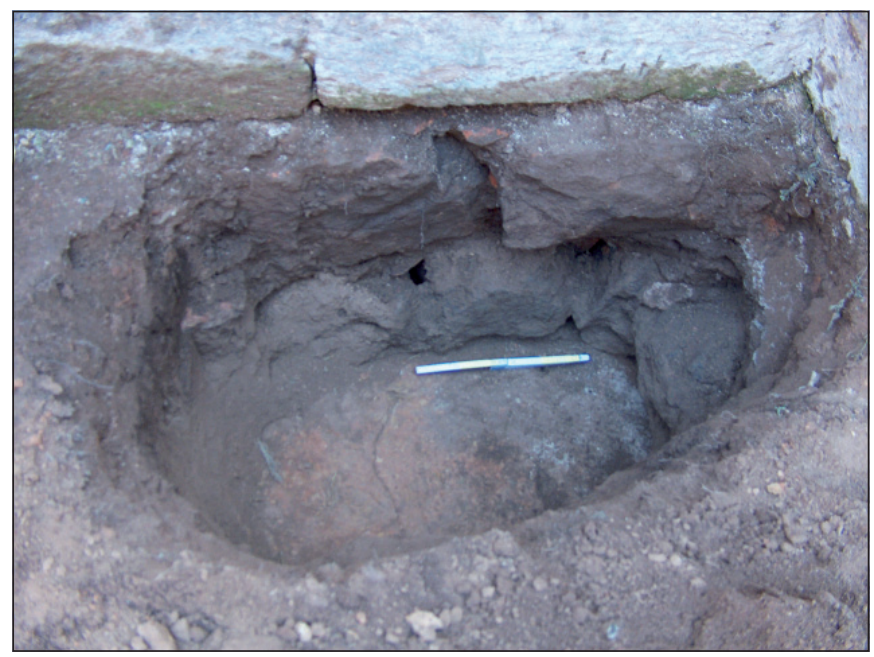

Fig. 5. Perimetrale sud, esplorazione della fondazione (saggio B), da nord (Foto C. Tonghini) centimetro fra la fondazione (US 1003), delimitata dal suo spiccato, e il primo filare dell'alzato (US 1004). La presenza di uno strato simile proprio sopra il piano roccioso suggerisce di interpretarlo come lo strato di regolarizzazione funzionale all'impostazione dell'alzato piuttosto che come un livello di abbandono del cantiere di costruzione ${ }^{12}$.

Sulla fondazione viene impostato l'alzato di questa prima Fase, identificato nell' area absidale interna (US 372, 374) e negli ambienti ad essa adiacenti per alcuni filari (Attività 2), e riconosciute per almeno un filare anche nella porzione inferiore interna delle pareti meridionale e settentrionale (Attività 3, Fig. 6). A questo livello (primo filare dell'alzato) la continuità costruttiva dei perimetrali sud e nord con gli avancorpi degli angoli sud-ovest e nord-ovest, e con il fronte ovest può solo essere ipotizzata; la mancata identificazione di un'interfaccia fra una ipotetica Fase 1 ed una ipotetica Fase 2 nella porzione ovest dell'edificio, corrispondente a quella attestata nell'area absidale (US 375) e sui perimetrali nord e sud, la apparente omogeneità delle strutture di questa porzione ovest (indicata all'interno dalla pezzatura e lavorazione dei conci, all'esterno dalla

12 Le strutture di fondazione esaminate in dettaglio nella fortificazione di Shayzar, Siria, attestano la pratica di stendere strati di terra fra le varie bancate della sostruzione, anche quando legate con malta di calce, e fra fondazione ed alzato: Tonghini 2012, p. 207, nota 129. 
Fig. 6. Parete interna sud: è visibile il taglio praticato nel filare più basso (Foto N. Montevecchi)

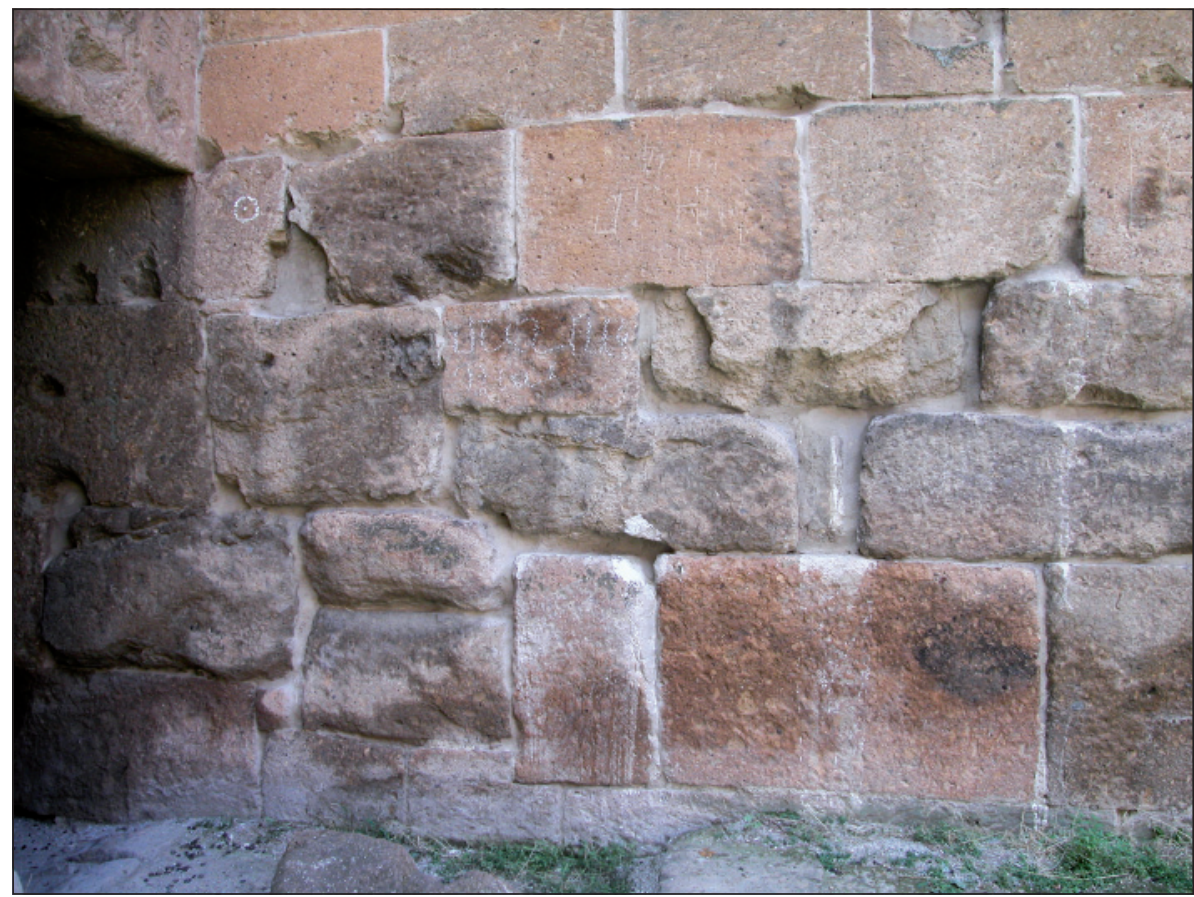

corrispondenza dei corsi e dal legame fra il corpo di nordovest ed il perimetrale nord) invitano senzaltro alla prudenza in questa fase dell'analisi. Se è dunque possibile che anche la porzione ovest sia stata fondata in questa Fase $1^{13}$, solo un approfondimento delle indagini consentirà di stabilirlo con certezza.

L'alzato di questa prima Fase segue dunque lo stesso andamento planimetrico dell'edificio attuale nell'area absidale, nella definizione degli ambienti laterali, e nei perimetrali nord e sud, compresa la messa in opera delle paraste interne dei fronti sud e nord, mentre è solo ipotizzabile nella porzione ovest dell'edificio (Figg. 2, 4, 19).

L'edificio impiantato nella Fase 1 è interessato da un fenomeno di dissesto (Attività 4): nella parte interna dell'abside si può rilevare una progressiva inclinazione dei filari più bassi da nord verso sud, con il punto di massimo cedimento, stimabile intorno ai $30 \mathrm{~cm}$., nella porzione sud (US 372, 374, Figg. 3-4). Segni di dissesto si possono anche osservare negli ambienti adiacenti, sia in quello nord che in quello sud, con inclinazione dei filari, anche se meno marcata rispetto a quella dell'abside, ed un frequente allentamento dei

${ }^{13}$ Negli ambienti adiacenti l'abside si è rilevato che il corso più basso visibile (ma non è possibile stabilirne la posizione rispetto ad una eventuale struttura di fondazione, in assenza di saggi esplorativi) mette in opera materiale di piccola pezzatura, con le lunghezze che sono spesso simili alle altezze (ad esempio, US 420); la presenza di un corso realizzato con materiale simile nei filari più bassi è stata anche osservata nell'ambiente di sud-ovest, ma non è stato possibile verificarne la continuità costruttiva con il resto della struttura e pertanto comprovare la contemporaneità di questa parte con la Fase 1. giunti. Questo fenomeno provoca presumibilmente una temporanea interruzione dei lavori (Attività 5 , US 375, Fig. 4) e l'applicazione di misure correttive (Fase 2).

Il dissesto è stato riconosciuto solamente nella parte interna dell'abside e all'interno degli ambienti laterali; in considerazione del fatto che i fronti esterni corrispondenti non ne conservano le tracce, questi sono stati attribuiti agli interventi di ripresa della successiva Fase 2 (Figg. 4, 7-8, 13-14, 19).

Siamo consapevoli della parziale forzatura che questa interpretazione comporta a livello costruttivo: si va sostanzialmente ad ipotizzare che le murature della Fase 1 si siano conservate sul solo paramento interno, mentre gli esterni sono stati ricostruiti dopo un fenomeno di dissesto, nella Fase 2. Tuttavia l'esiguità dell'evidenza esaminata e l'impossibilità di procedere a verifiche puntuali non ci ha permesso di cogliere compiutamente l'entità del dissesto che va ad interessare le murature attribuite alla Fase 1 e la natura delle operazioni di ripresa attribuite alla Fase 2; pertanto, le osservazioni qui presentate possono solo condurre ad ipotesi che necessitano di ulteriori approfondimenti.

E' anche importante osservare che una delle caratteristiche costruttive dell'intero edificio, verificata nelle porzioni meglio esplorabili, e dunque quelle relative alle fasi successive, consiste nella mancata corrispondenza fra i filari del fronte esterno e quelli del fronte interno; risulta così particolarmente difficoltoso cogliere una eventuale corrispondenza fra le interfacce rilevate all'esterno e quelle 


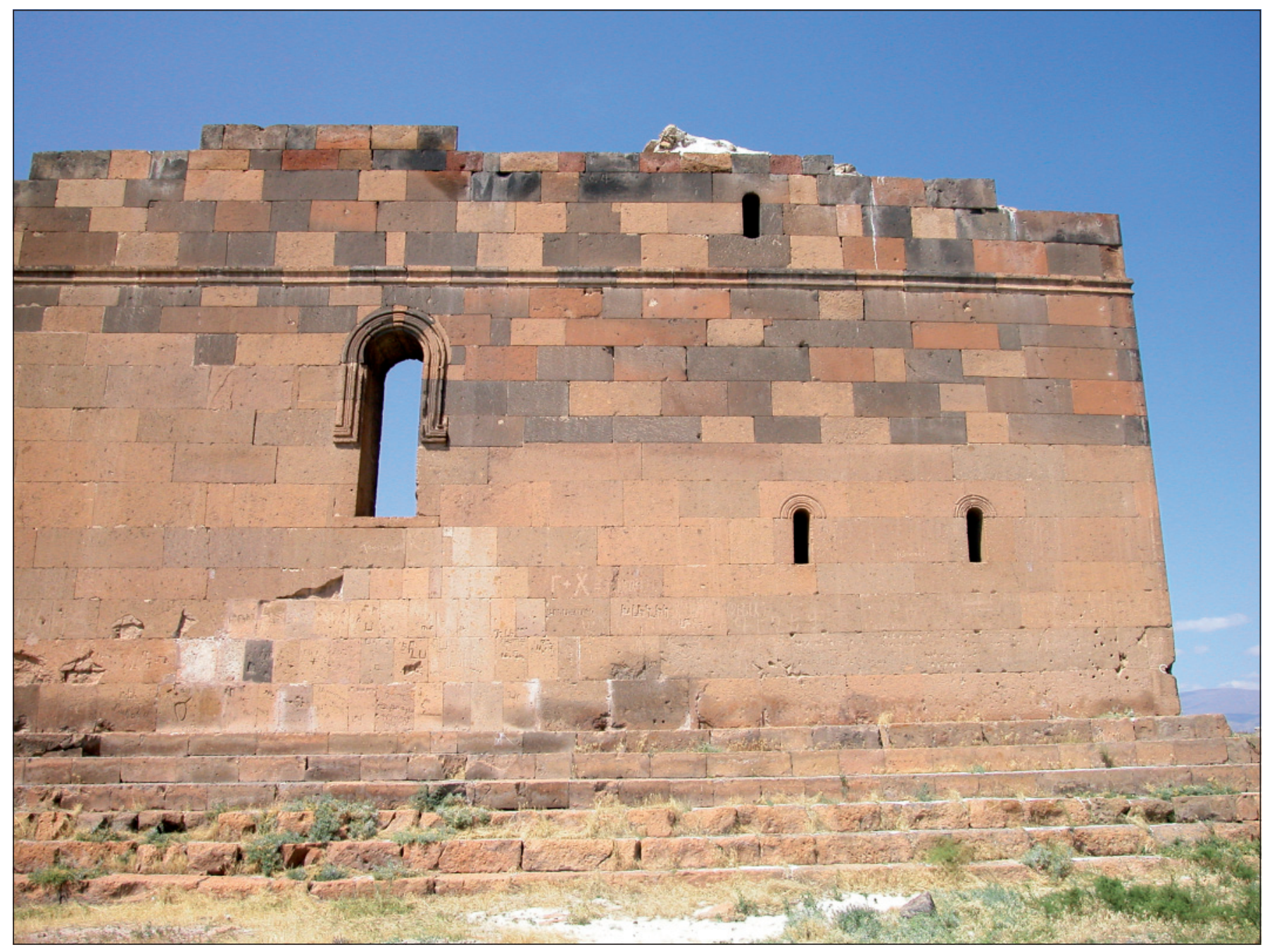

Fig. 7. Parete absidale esterna, porzione nord, da est (Foto N. Montevecchi)

rilevate all'interno e definire con precisione la natura degli interventi della Fase 2, e cioè stabilire se la ricostruzione abbia potuto interessare il solo paramento esterno. In considerazione di questa caratteristica, nell'impossibilità di procedere ad una esplorazione della sezione muraria in corrispondenza dell'abside, e dunque di delimitare lo spessore delle strutture attribuite a ciascuna Fase, e soprattutto sulla base della notevole omogeneità del paramento esterno (Figg. 7, 13), è stata ritenuta più convincente l'ipotesi di attribuire alla Fase 1 le sole porzioni interne del corpo absidale, e di associare le porzioni esterne con la ricostruzione intercorsa nella Fase 2; inoltre, un primo esame macroscopico delle malte di allettamento, da sottoporre a puntuali verifiche, mostra che la porzione interna risulta allettata con malta diversa rispetto a quella esterna.

I paramenti interni, gli unici dunque che possiamo attribuire con certezza a questa fase costruttiva, si caratterizzano per la messa in opera di materiale squadrato in tufo vulcanico $^{14}$; i conci utilizzati per l'abside (Fig. 3) e per gli ambienti adiacenti sembrano presentare una pezzatura minore (altezze medie fra i 30 e i $45 \mathrm{~cm}$., con un filare dell'altezza di $20 \mathrm{~cm}$.) rispetto ai conci utilizzati nei perimetrali nord e sud (con altezze fra i 50 e i $65 \mathrm{~cm}$.), relativi questi ultimi al solo primo filare (Figg. 3, 6); solo negli stipiti che definiscono le due aperture di accesso agli ambienti laterali dell'abside (US 396, 419) si riscontrano conci di notevoli dimensioni (Figg. 3-4 $)^{15}$.

Nell'abside e negli ambienti adiacenti i conci della Fase 1 sono di dimensioni minori anche rispetto a quelli

${ }^{14}$ Il litotipo è esaminato e discusso da Bessac 2011, pp. 384-386; Bessac, c.s., cap. 1. Bessac 2011 descrive in dettaglio ed esamina i sistemi di cavatura, preparazione, finitura e posa in opera del materiale nell'intera regione, con specifici riferimenti anche a Ererouk.

${ }^{15}$ In cantiere è stata registrata la differenza nella pezzatura dei conci, ma si era rimandata la puntuale verifica delle misure alla successiva fase di studio e definizione delle tipologie murarie; le misure qui riportate sono quelle che si possono ricavare dai rilievi disponibili ad oggi. 


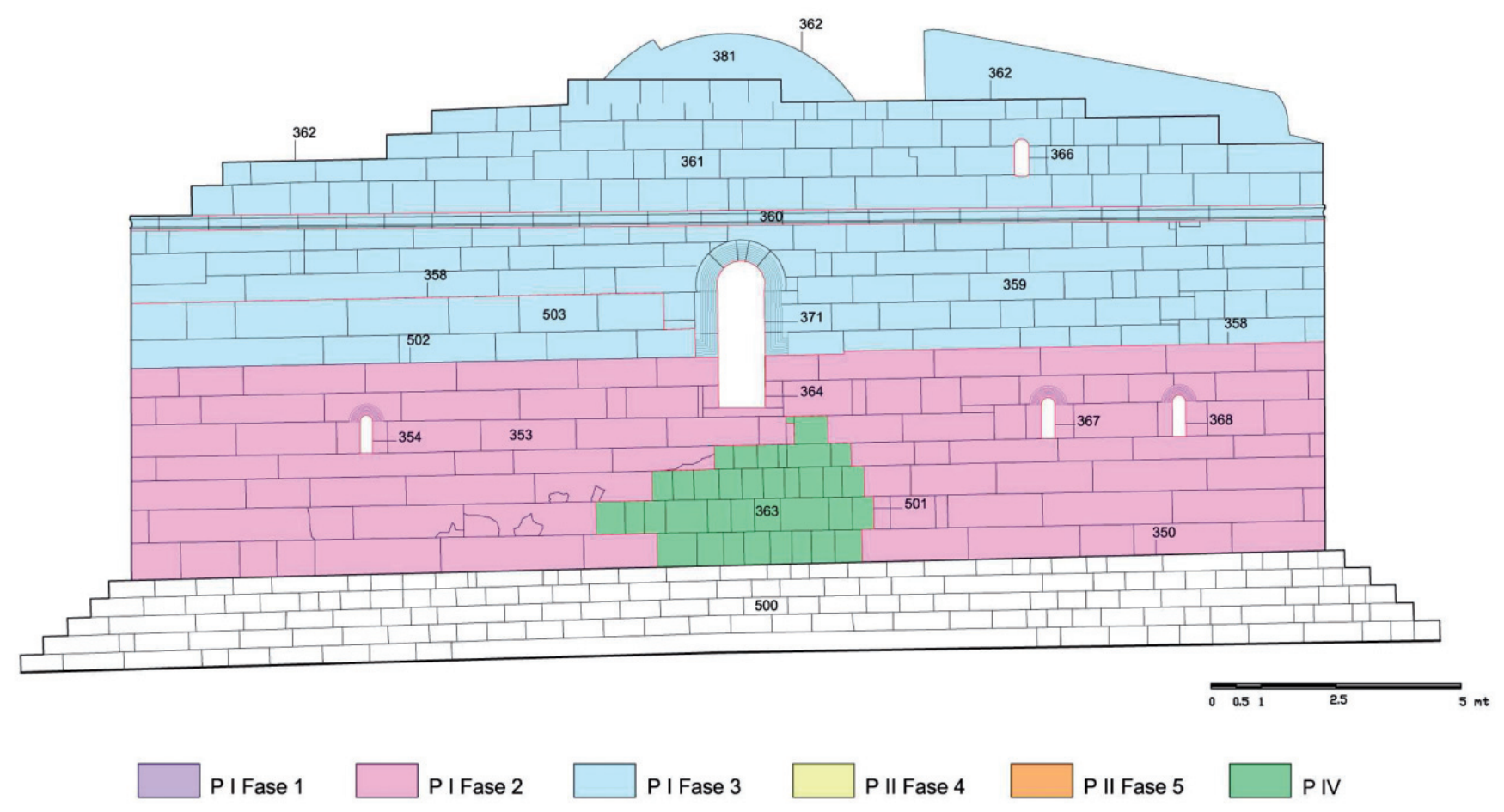

Fig. 8. Prospetto est esterno: lettura stratigrafica (rilievo H. Romanazzi, caratterizzazione archeologica N. Montevecchi)

dei corsi superiori che vengono attribuiti alla ricostruzione della Fase 2, sopra l'interfaccia US 375, soprattutto per quanto riguarda le lunghezze. Nei perimetrali nord e sud, invece, solo il primo filare dell'alzato è stato attribuito a questa Fase 1, e dunque non sono possibili analoghi raffronti fra le diverse fasi.

E' anche possibile osservare negli ambienti laterali dell'abside la ricerca sistematica di un legame fra i paramenti delle angolate, come avverrà nella successiva Fase 2.

Questa Fase si interrompe in seguito a problemi di cedimento fondale che interessano la parte del corpo absidale (Attività 4, 5).

Fase 2 (Figg. 4, 8, 14, 19, colore rosa)

Attività 6: ripresa del dissesto dell'abside e degli ambienti laterali e proseguimento della costruzione dell'alzato (abside: US 376) (Figg. 3-4, 7-8, 13-14, 19);

Attività 7: ripresa della costruzione dei perimetrali con taglio dei conci del filare della Fase 1 sul fronte interno sud e nord, porzione inferiore, ed esterno (Figg. 6, 14);

Attività 8: avanzamento della costruzione dei perimetrali con materiale di pezzatura leggermente inferiore (Figg. 4, 8, 14, 19);

Attività 9: costruzione o ripresa della porzione ovest, inclusi i corpi aggettanti, parte inferiore, con materiale di grande pezzatura (Figg. 9-11, 14-15, 19);
Attività 10: interruzione della costruzione della torre di nord-ovest, probabile cedimento fondale (Figg. 10, 14-15);

Attività 11: interruzione del cantiere Fase 2 (Figg. 4, 8, 10, 14, 19).

Nel corso della Fase 1 l'edificio in costruzione era stato interessato da un fenomeno di cedimento fondale, rilevato nella parte interna dell'abside e all'interno degli ambienti adiacenti (Attività 4), che aveva portato all'interruzione dei lavori (US 375, Attività 5).

Nella Fase 2 vengono introdotte misure correttive (Attività 6): per riprendere l'orizzontamento nel paramento interno dell'abside vengono messi in opera conci di forma trapezoidale (US 376; Figg. 3-4); lo stesso avviene, anche se più limitatamente, negli ambienti adiacenti l'abside.

Come rilevato più sopra, il paramento esterno dell'intero corpo absidale non mostra tracce di dissesto, e la muratura risulta omogenea fino all'interfaccia con la successiva Fase 3 (US 353, 508; Figg. 3-4, 7-8, 13-14, 19); un primo esame macroscopico delle malte di allettamento sembra indicare che la malta utilizzata per il paramento interno dell'abside interessato dal dissesto (Fase 1) sia diversa da quella utilizzata per l'esterno ${ }^{16}$. Nell'impossibili-

${ }^{16} \mathrm{Nel}$ corso della campagna 2005 si è proceduto al prelievo di alcuni campioni, ancora non sottoposti ad indagini di laboratorio. 


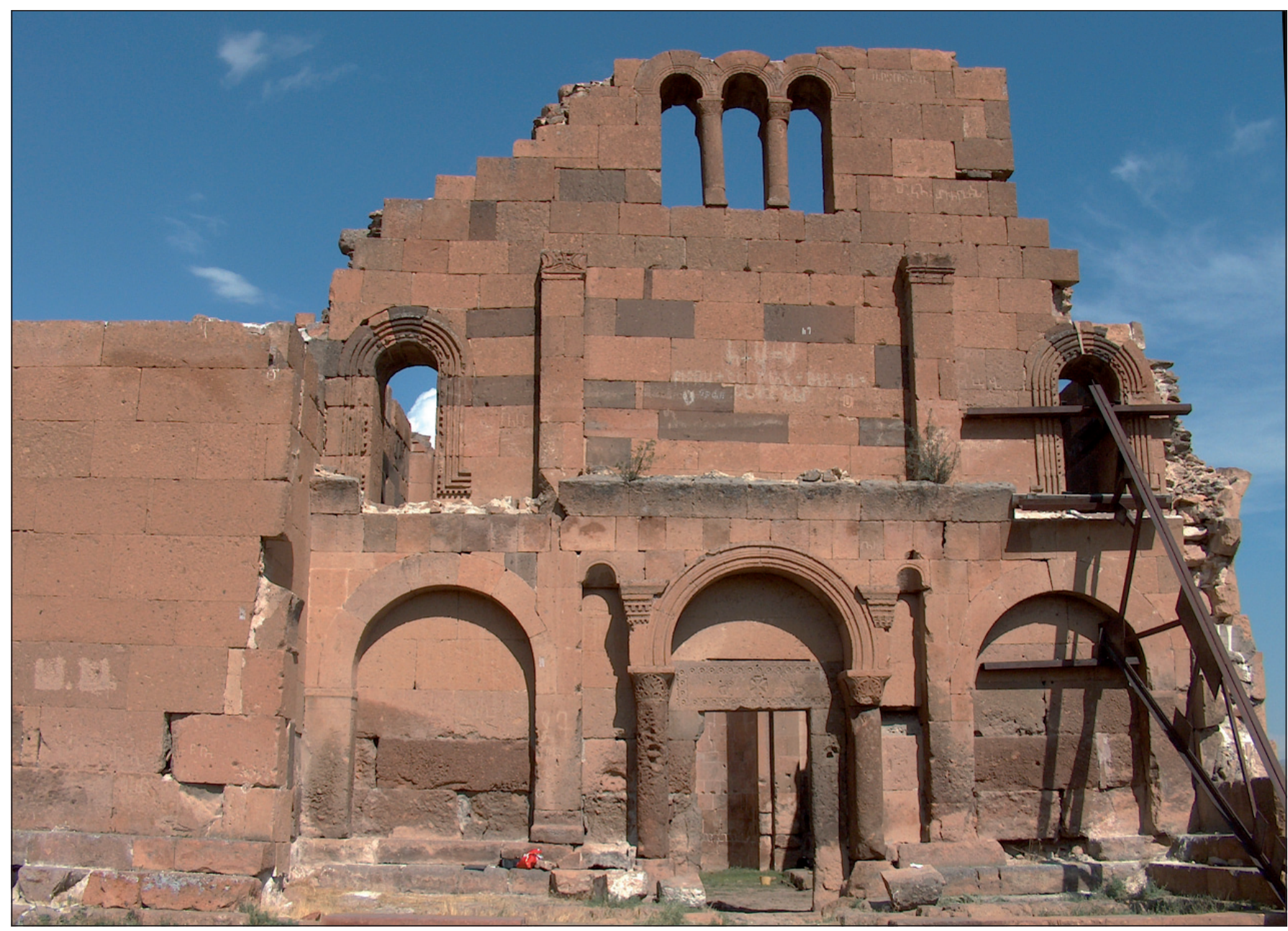

Fig. 9. Facciata ovest, da ovest (Foto C. Tonghini)

tà di procedere ad un esame della sezione muraria, e considerando che una delle caratteristiche tecniche che si riscontra nelle fasi meglio leggibili è quella della mancata corrispondenza fra i corsi interni e quelli esterni, ci è sembrato di potere ipotizzare un intervento di ripresa limitato al solo fronte esterno (si veda supra).

In prossimità dell'ammorsatura tra le pareti perimetrali meridionale e settentrionale e la parete absidale è stata riscontrata una interfaccia che potrebbe corrispondere all'interruzione dei lavori determinata dal dissesto della zona absidale della Fase 1, e delimitarne la ripresa (Attività 7, Fig. 6). La quota dell'interfaccia dei perimetrali è più bassa rispetto a quella individuata nel corpo absidale; questa differenza potrebbe derivare dalle pratiche costruttive, che tendevano con ogni probabilità a privilegiare l'avanzamento dei lavori nella zona absidale. La posizione pressoché simmetrica di questa interfaccia sul lato sud rispetto a quella del lato nord potrebbe avvalorare la sua interpretazione in funzione di una momentanea interru- zione dei lavori piuttosto che riferibile ad un evento traumatico tipo crollo.

In questa Fase 2 vengono dunque costruite la porzione inferiore e mediana delle pareti perimetrali sud e nord (US 155, 160, 236, 183, 199, 515, 212, 213; Attività 78), ripreso il dissesto del corpo absidale sul fronte interno e ricostruita l'intera parete esterna (US 353, 508, Attività 6).

E' riferibile a questa fase anche la realizzazione della corrispondente porzione della facciata ovest e delle torri laterali (Attività 9, Figg. 9-11, 14-15). La contemporaneità costruttiva tra la facciata e le torri è verificabile all'interno per la continuità muraria tra le strutture (Fig. 11); la contemporaneità fra le torri occidentali ed il corpo della chiesa è verificabile sul fronte nord nell'ammorsatura fra il paramento esterno nord e quello esterno della torre di nord-ovest; su quello sud in corrispondenza dell'ammorsatura tra la parete perimetrale esterna della chiesa e il fianco orientale della torre sud-ovest, oggi completamente demolito (Fig. 12). 


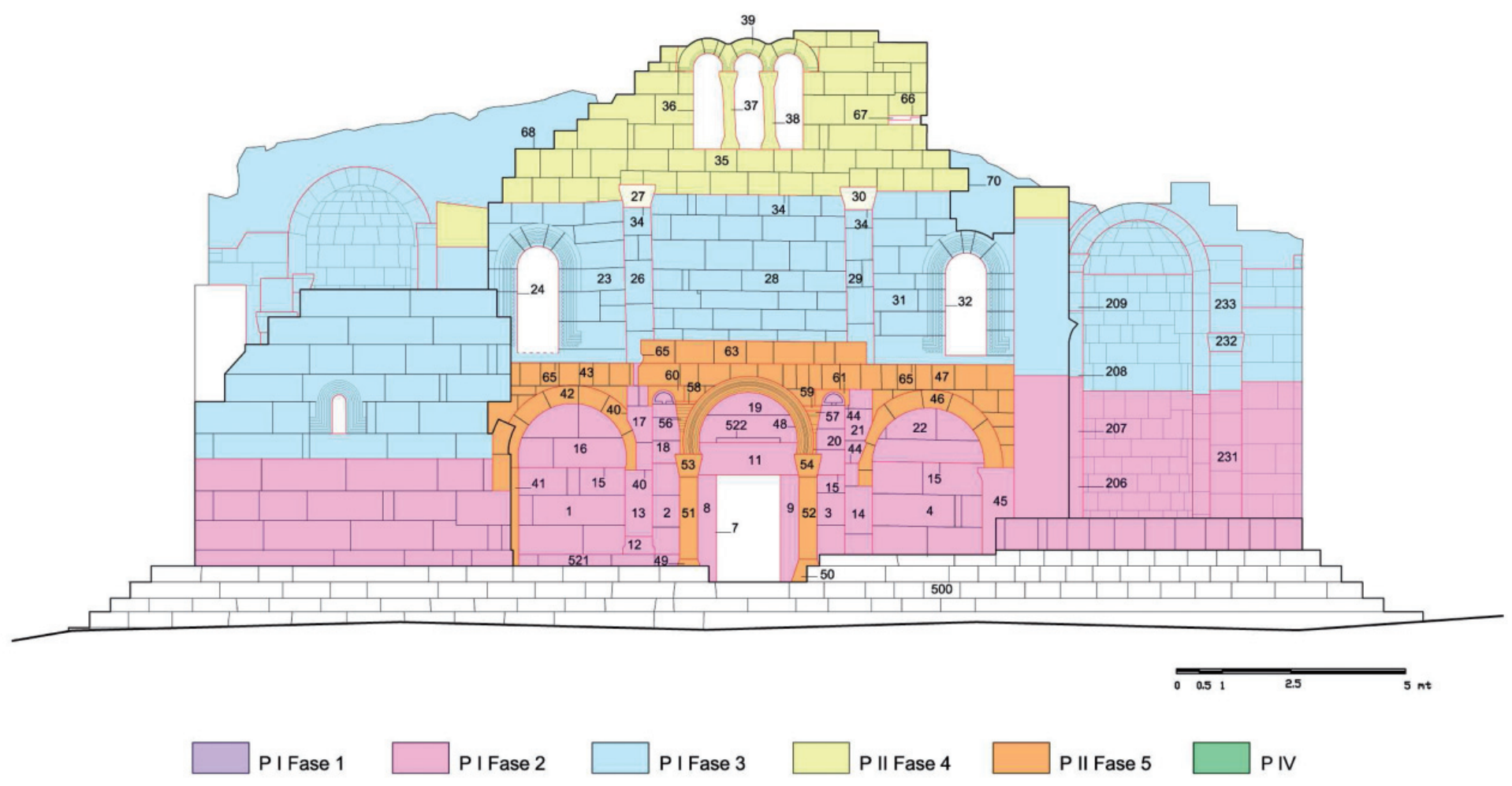

Fig. 10. Prospetto ovest esterno: lettura stratigrafica (rilievo H. Romanazzi, caratterizzazione archeologica N. Montevecchi)

La differenza tipologica (dimensioni e litotipo del materiale impiegato) riscontrata nelle murature riferite a questa Fase 2 è stata ricondotta ad Attività distinte (Attività $6,7,8,9)$ : questa differenza potrebbe essere determinata dall'approvvigionamento del materiale ma anche legata alle pratiche costruttive adottate, con un progressivo ridimensionamento della pezzatura del materiale nei filari più alti: la porzione inferiore è infatti costruita con conci di grandi dimensioni organizzati su filari orizzontali e paralleli, mentre quella mediana è costruita con conci di dimensioni leggermente più contenute, anch'essi disposti su filari orizzontali e paralleli. Oltre che sui fronti esterni sud e nord, e sul fronte interno ovest (Fig. 11), questa differenza è stata rilevata anche all'interno degli ambienti laterali dell'abside, mentre non è percepibile nell'intero fronte esterno del corpo absidale.

L'unico elemento che solleva qualche dubbio sulla unicità di fase è l'evidente differenza dello stato di degrado della superficie della faccia a vista dei conci tra la porzione inferiore e quella mediana riscontrato sul lato esterno sud (Figg. 12-14, 17) ${ }^{17}$.

${ }^{17}$ I conci della porzione inferiore mostrano un elevato stato di degrado, causa della pressoché totale sostituzione, nei restauri del 1948 (Kouymjian 1977, p. 29), del materiale del paramento esterno della parete perimetrale meridionale. Andrebbe chiarita la causa di tale degrado e verificato se questa possa corrispondere all'utilizzo di un diverso litotipo.
In questa Fase vengono definite e completate una serie di aperture nel corpo absidale: due finestre nell'ambiente sud, una sul lato sud (US 150; Fig. 13) ed una sul lato est (US 354); due finestre nell'ambiente nord del corpo absidale affacciate ad est (US 367 e US 368; Fig. 7). Come già emerso in altre pubblicazioni che si sono diffusamente occupate anche degli aspetti stilistici dell'architettura di Ererouk, si può rilevare un diverso trattamento nella decorazione degli stipiti e delle coperture di queste finestre, in particolare per le due finestre dell'ambiente sud dell'abside, con la modanatura che si limita alla sola copertura nella finestra est (US 354) e la modanatura che invece interessa anche gli stipiti nella finestra sud (US 150); le due finestre sono certamente da attribuire ad una medesima fase, e lo conferma il perfetto legame che si può osservare all'interno nel paramento delle rispettive murature (Figg. 8, 14).

I portali sovrastati da pseudo-protiri della facciata sud (US 185, 225), così come quello della facciata ovest (US 7), parzialmente trasformato nel Periodo II, Fase 5, sono riferibili alla Fase 2 (Figg. 9, 16-17). La muratura sopra l'architrave sembra costruita partendo dalle due estremità opposte della campata, costruendo due porzioni che si incontrano al centro, in corrispondenza dell'apertura ${ }^{18}$; il

${ }^{18}$ Questa pratica costruttiva si può osservare anche sopra il portale ovest, sul fronte interno (Fig. 11). 
punto di raccordo fra le due parti, caratterizzato da una non perfetta corrispondenza dell'altezza dei conci, è perfettamente occultato dagli pseudo-protiri (Fig. 17); questo dettaglio ci sembra confermare la contemporaneità della costruzione degli pseudo-protiri con la muratura della Fase 2. Possiamo anche ricordare che l'esistenza di un legame costruttivo fra questa componente e la muratura retrostante è anche stato rilevato da Gandolfo (Gandolfo 1982, p. 70).

Per quel che riguarda lo stilobate a gradoni, è probabile che la sua costruzione sia riferibile alla Fase 2 (Figg. 7, $12-13,15)$. Tuttavia, poichè non è stato possibile estendere l'analisi sul campo a questa importante componente, questa non può essere inclusa nella presente discussione.

Nella sequenza qui delineata si può prospettare un arresto del cantiere della Fase 2 al livello di imposta delle aperture dei fronti sud (US 200) ed ovest, ed in corrispondenza di un cedimento nella torre di nord-ovest (Figg. 4, 8, $10,14,19)$.

Fase 3 (Figg. 4, 8, 10, 14, 19, colore blu)

Attività 12: ripresa dell'orizzontamento sul fronte esterno sud della torre di nord-ovest e proseguimento della costruzione (Figg. 2, 10, 14);

Attività 13: ripresa della costruzione dei fronti nord, sud e ovest, con impostazione delle aperture (Figg. 9-10, 12-14, 17);

Attività 14: realizzazione delle aperture sui fronti ovest $\mathrm{e}$ sud (Figg. 9-10, 12-14, 17);

Attività 15: ripresa della costruzione del corpo absidale fino all'imposta dei catini delle tre absidi e alla cornice marcapiano del secondo livello (Figg. 3-4, 7-8, 13-14, 19);

Attività 16: costruzione del secondo livello del corpo absidale e dei catini absidali (Figg. 3-4, 7-8, 13-14, 19);

Attività 17: costruzione dei pilastri interni (Figg. 2, 18);

Attività 18: costruzione delle arcate di partizione interna delle navate (Figg. 3-4, 11);

Attività 19: avvio/costruzione delle volte di copertura delle navate, con archi traversi;

Attività 20: avvio/costruzione delle volte di copertura dei portici, con archi traversi (Figg. 12-14, 17);

Attività 21: interruzione dei lavori?

L'avanzamento del cantiere della Fase 2 si interrompe, con ogni probabilità, in vista della definizione delle aperture sui lati ovest e sud (US 200, Attività 11). Che questa interruzione sia da mettere in relazione con l'avanzamento dei lavori piuttosto che con una operazione di ricostruzione che fa seguito ad un evento distruttivo trova conferma nell'andamento piuttosto regolare ed orizzontale dell'interfaccia (US 200, Fig. 14) e nel legame costruttivo che si riscontra anche a questo livello, e già osservato nella Fase 2, fra la facciata ovest e gli avancorpi ovest (Fig. 9), e fra l'avancorpo di sud-ovest ed il fronte sud (Fig. 12); nessuna modifica sembra essere apportata all'articolazione planimetrica dell'edificio in questa Fase 3.

L'interfaccia fra la Fase 2 e la Fase 3 (US 200) è inoltre sottolineata nelle paraste della parete meridionale esterna da un leggero arretramento dei conci rispetto al filo muro della Fase sottostante (Fig. 14).

Nella precedente Fase 2 si era anche registrata una interruzione dei lavori nell'avancorpo di nord-ovest, probabilmente a seguito di un cedimento fondale che si rileva sulla facciata sud (Attività 10, Figg. 10, 14); anche questo dissesto, come nel caso dell'abside (Fase 2, Attività 6), viene ripreso nella Fase 3 mettendo in opera conci di forma trapezoidale (Attività 12, Fig. 14) ${ }^{19}$.

In questa Fase 3 si procede dunque al completamento dei fronti sud, ovest e nord, con due finestre che si aprono a ovest (US 24, 32, Figg. 9-10) e quattro a sud (US 196, 203, 204, 217, Figg. 14, 17), mentre il fronte nord rimane cieco; vengono anche realizzate le aperture degli avancorpi ovest, di cui rimangono solo quelle dell'ambiente di nordovest (Figg. 10, 15). Sui lati nord, ovest e sud proseguono i lavori per la definizione dei porticati coperti, attestati dalla presenza delle paraste in fase con i perimetrali (si veda infra).

Vengono definite le coperture delle torri ovest e degli ambienti adiacenti l'abside, con volte a botte, e vengono costruiti i catini dell'abside e delle absidiole laterali (Figg. $3-4,7-8,13-14,19)$. Viene anche costruito un secondo livello sopra gli ambienti laterali all'abside (Attività 16), di cui rimane anche un'apertura sul fronte est del corpo nord (Fig. 8).

Vengono quindi definite le strutture di partizione interna delle navate, con la messa in opera delle arcate impostate sulle paraste di testata ad est e a ovest (Attività 18, Figg. 3-4, 11) e su una serie di pilastri cruciformi che suddividono la pianta in tre navate (Attività 17, Figg. 2, 18). Gli interventi del successivo Periodo II non ci consentono una verifica sulla effettiva costruzione delle murature di partizione che vanno ad impostarsi sulle arcate

\footnotetext{
${ }^{19}$ Bessac rileva un cambiamento nella tipologia di materiale impiegato al di sopra dell'interfaccia di interruzione dei lavori, indicato anche da una precisa incisione sui conci: Bessac c.s., 5.6.1.
} 


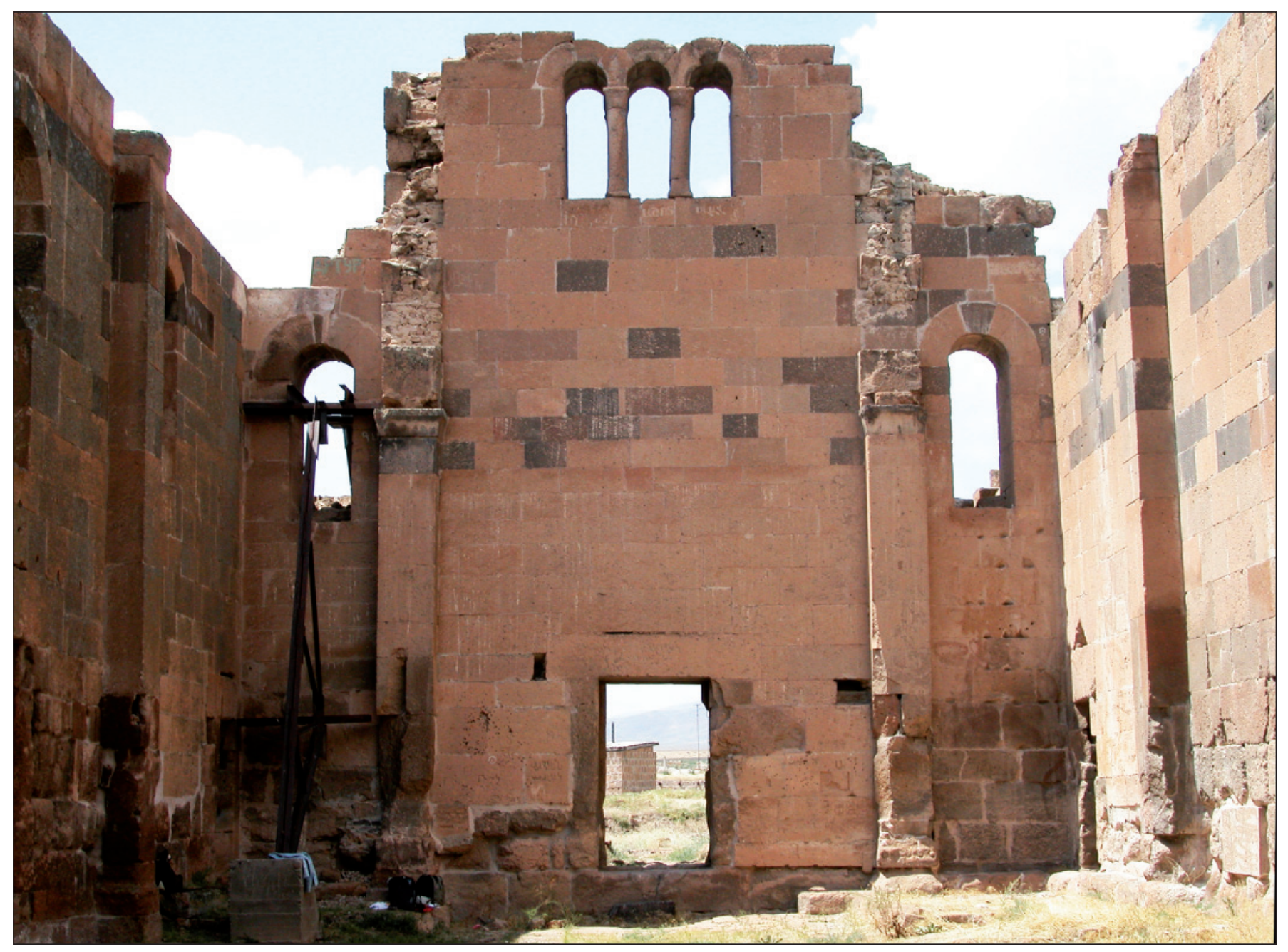

Fig. 11. Facciata ovest, interno, da est (Foto N. Montevecchi)

delle navate: i lacerti di muratura visibili oggi sul fronte ovest si legano infatti alle strutture della successiva Fase 4 (Fig. 11).

Gli interventi di questa Fase 3 sono caratterizzati da una muratura tipologicamente diversa da quella impiegata nelle Fasi precedenti. Si riscontra innanzitutto l'introduzione di materiale di almeno due diversi litotipi, oltre a quello più chiaro già utilizzato nelle fasi precedenti (Figg. $3,7,9,11,13,17)$. E' soprattutto nel corpo absidale che i nuovi litotipi sembrano prevalere su quello più chiaro (Attività 15 e Attività 16; Figg. 3, 7).

Bessac nota nel corpo absidale anche un diverso trattamento nella finitura degli spigoli dei conci, che presentano angoli smussati (Bessac c.s., 5.1.2). Non è inverosimile che un intervento sulla zona absidale abbia caratteristiche di specificità più marcate che altrove, anche nella scelta del materiale, e, in assenza di altri elementi, l'intervento sull'abside ci è sembrato in linea con il cantiere della Fase 3. Si può anche osservare come l'introduzione di materiale di diverso litotipo sia stata anche sfruttata nella ricerca di un effetto bicromatico nelle ghiere delle tre absidi.

Soprattutto sul fronte sud si riscontra una minore regolarità nella forma e nelle dimensioni dei conci rispetto a quanto osservato nella precedente Fase 2, con conci di altezze diverse nello stesso filare e ritagli di adattamento di molti conci (in particolare US 167, 169, 184, 201, 202: Figg. 14, 17). Se è certo possibile che in questa Fase siano intervenute maestranze diverse rispetto a quelle che hanno operato nella Fase 2, ci sembra tuttavia che questa apparente irregolarità nel modulo dei conci sia prima di tutto da ricondurre alla presenza delle aperture, che introducono forzatamente una perturbazione nella regolarità della tessitura muraria; tale irregolarità non si riscontra infatti sul fronte nord della stessa Fase, privo di aperture. L'intervento di maestranze specializzate per l'esecuzione delle finestre, 
una pratica tutt'altro che insolita nei cantieri medievali, viene confermata dall'analisi di Bessac ${ }^{20}$.

Molti autori in passato hanno sottolineato la diversità riscontrabile nella tecnica e nella decorazione delle varie finestre della basilica (Figg. 7-10, 12-14, 17) ${ }^{21}$ : alcune presentano gli stipiti realizzati negli stessi conci del paramento (US 24, 32, 217; Figg. 10, 14), in altre gli stipiti si raccordano tramite conci appositamente ritagliati ai muri di rinfianco (US 196, 203, 204; Fig. 14); in alcuni casi l'arco di copertura, estradossato, presenta una fascia di raccordo con il paramento (US 24, 32, 217; Figg. 10, 14), in altri l'estradosso coincide con l'elemento decorativo modanato (US 196, 203, 204; Fig. 14); la cornice modanata degli stipiti e della copertura presenta leggere differenze, con la presenza o meno di una cornice a dentelli, con le modanature di diverso numero e spessore, o posizionate ad un diverso intervallo (Figg. 7-10, 12-14, 17).

Anche la monofora dell'abside (US 364, Figg. 7-8) presenta un trattamento a se stante: già impostata per almeno due corsi nella precedente Fase 2, viene ultimata seguendo una diversa logica costruttiva e decorativa in questa Fase 3: nella Fase 2 gli stipiti erano definiti negli stessi conci che costituiscono il paramento, e non presentano un diverso trattamento decorativo rispetto a questi; nella Fase 3 la finestra viene completata utilizzando dei conci a decorazione modanata per gli stipiti, raccordandoli al paramento attraverso una serie di elementi ritagliati ad hoc.

Queste diversità tipologiche non ci sono sembrate sufficienti per ricomporre altrimenti la sequenza costruttiva, e, privilegiando la logica stratigrafica, preferiamo metterle in relazione con l'intervento di maestranze diverse nell'ambito di uno stesso cantiere. Solo l'approfondimento delle indagini, con un'analisi microstratigrafica e l'integrazione dei dati raccolti con l'analisi tecnica di dettaglio completata da Bessac, porterà forse in futuro a dare conto più esaurientemente di tali diversità.

In questa stessa Fase viene avviata la costruzione delle pareti di partizione interna delle navate, con la costruzione degli archi di valico (Attività 18; Figg. 3-4, 11) su cui andrà poi ad impostarsi la muratura, quest'ultima molto probabilmente non realizzata in questa Fase (si veda infra). Le arcate di partizione interna poggiavano su pilastri cruciformi (Attività 17), di cui solo quello est della partizione sud si è conservato (Figg. 2,18). Nella letteratura pregressa dedicata a Ererouk molte pagine sono state

${ }^{20}$ Bessac c.s., 5.1.4-5.1.5 (fronte orientale), 5.3.2 (fronte sud), 5.5.4 (fronte occidentale).

${ }^{21}$ Gandolfo 1982, pp. 70, 73-74; Bessac c.s., 5.1.4-5.1.5 (fronte orientale), 5.3.2 (fronte sud), 5.5.4 (fronte occidentale). consacrate alla discussione sulla forma dei pilastri della basilica, ed in molte piante ne compaiono con forma a $\mathrm{T}^{22}$. $\mathrm{Al}$ momento del nostro sopralluogo nella basilica dell'agosto del 2005 abbiamo potuto constatare la presenza del suddetto pilastro ancora in situ, sgombrarlo dagli accumuli che lo occultavano in parte ed esaminarlo in dettaglio. Il pilastro è già riportato in alcune delle piante pubblicate ${ }^{23}$ : Marr infatti aveva dato notizia del suo ritrovamento nel corso della campagna da lui condotta nell'estate del 1908, riportandone anche le misure. Gandolfo ripercorre puntualmente le tappe che hanno portato alla sostanziale perdita di questo prezioso dato ed innescato un dibattito sostanzialmente infondato che ha condotto alla elaborazione di piante con pilastri di forma differente ${ }^{24}$.

Per quanto riguarda la sistemazione dell'area occidentale antistante la facciata, il crollo della porzione sommitale delle torri laterali e le trasformazioni che hanno interessato la parte superiore della facciata nel Periodo II, Fase 4, limitano fortemente la leggibilità dell'evidenza. Tuttavia, alcuni elementi sembrano riferibili se non alla realizzazione, almeno alla progettazione di un porticato ritmato da archeggiature già in questa Fase 3, Periodo I: le due paraste ancora in situ sulla facciata (US 26, 29, Fig. 10) potrebbero infatti essere relative all'imposta di una volta di copertura, come nel caso dei portici laterali sud e nord; la copertura del portico di questa Fase 3 era progettata per impostarsi ad una quota molto più alta rispetto a quella del portico del Periodo II, Fase 5: la volta poteva impostarsi ad est sulla facciata ovest stessa, con archi traversi innestati sulle paraste (US 26, 29, Figg. 2, 10), e ad ovest su un sistema ad arcate, forse a doppio ordine. Infatti, all'estremità ovest del muro sud dell'avancorpo di nord-ovest è conservata una parasta, trasformata in parte nel corso dei rimaneggiamenti del Periodo II, Fase 5, che viene indubbiamente definita in questa Fase 3 (Figg. 10, 14-15) ${ }^{25}$; sulla parasta doveva impostarsi un arco ed una muratura che correva in direzione nord-sud: sono ancora evidenti sul

\footnotetext{
22 Alpago-Novello 1977, pp. 21-22; Gandolfo 1982, p. 67.

${ }^{23}$ Documenti di Architettura Armena 9, 1977, p. 45.

${ }^{24} \mathrm{La}$ notizia della descrizione del pilastro da parte di Marr viene segnalata e discussa da Gandolfo 1982, p. 67 e nota 313. Gandolfo sottolinea come Thoramanian dovesse esserne a conoscenza, visto che arrivò ad elaborare una pianta con pilastri cruciformi che venne tuttavia pubblicata solamente nel 1942 . Strzygowski non dovette comprendere che i dati forniti da Thoramanian si basavano sul lavoro di Marr, ed introdusse l'ipotesi dei pilastri a forma di T, innescando sostanzialmente il dibattito. Gandolfo 1982, p. 67.

L'arch. Casnati ha fornito a chi scrive una sintesi in inglese del testo dell'Archivio Marr, ma qui non siamo stati in grado di identificare le notizie riguardanti il pilastro.

${ }^{25}$ Sul fronte nord della torre di sud-ovest è conservato almeno un corso di una analoga parasta.
} 


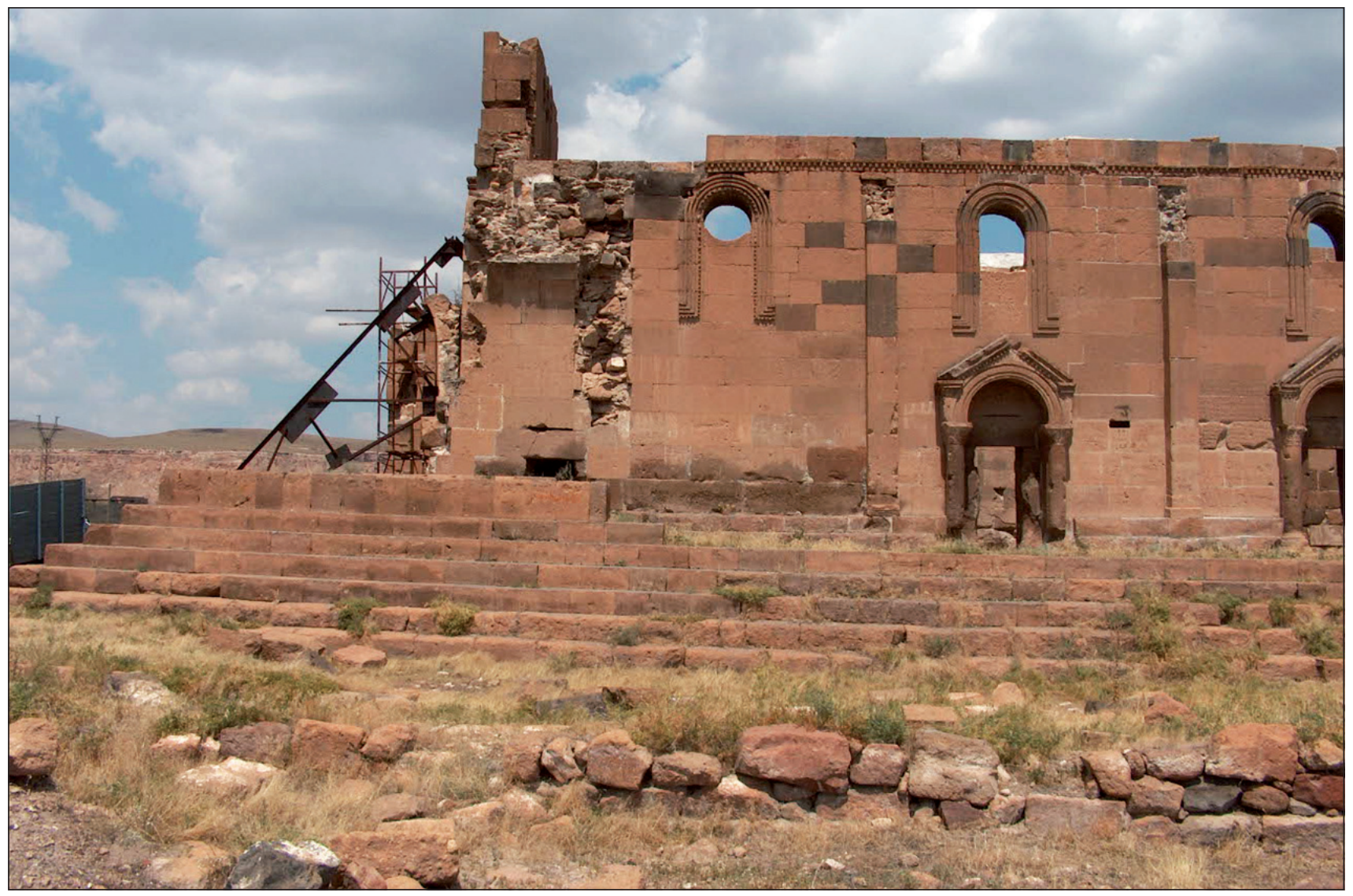

Fig. 12. Facciata sud, porzione ovest (visibile parte dell'interno della torre di sud-ovest), da sud (Foto C. Tonghini)

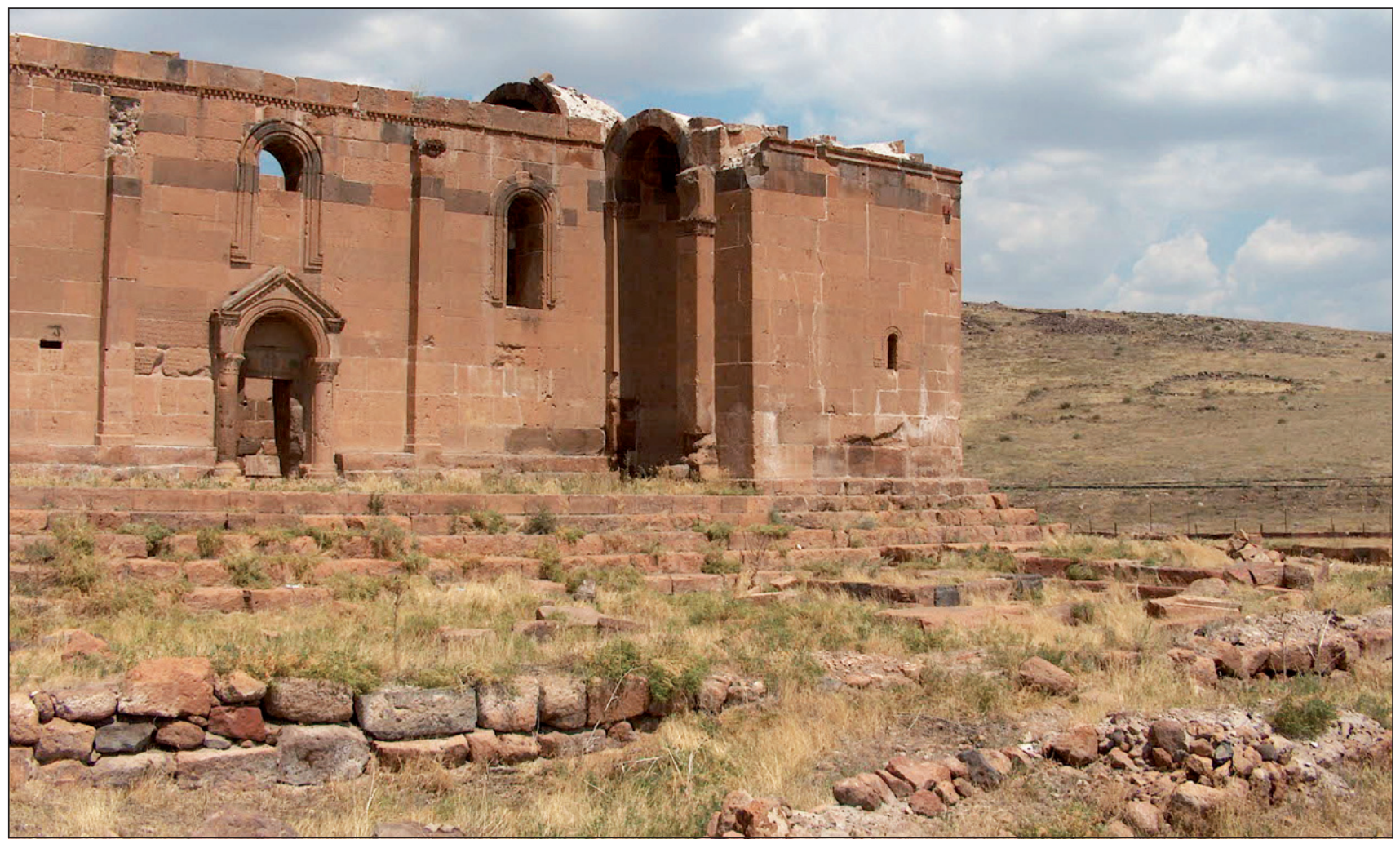

Fig. 13. Facciata sud, porzione est, da sud-ovest (Foto C. Tonghini) 


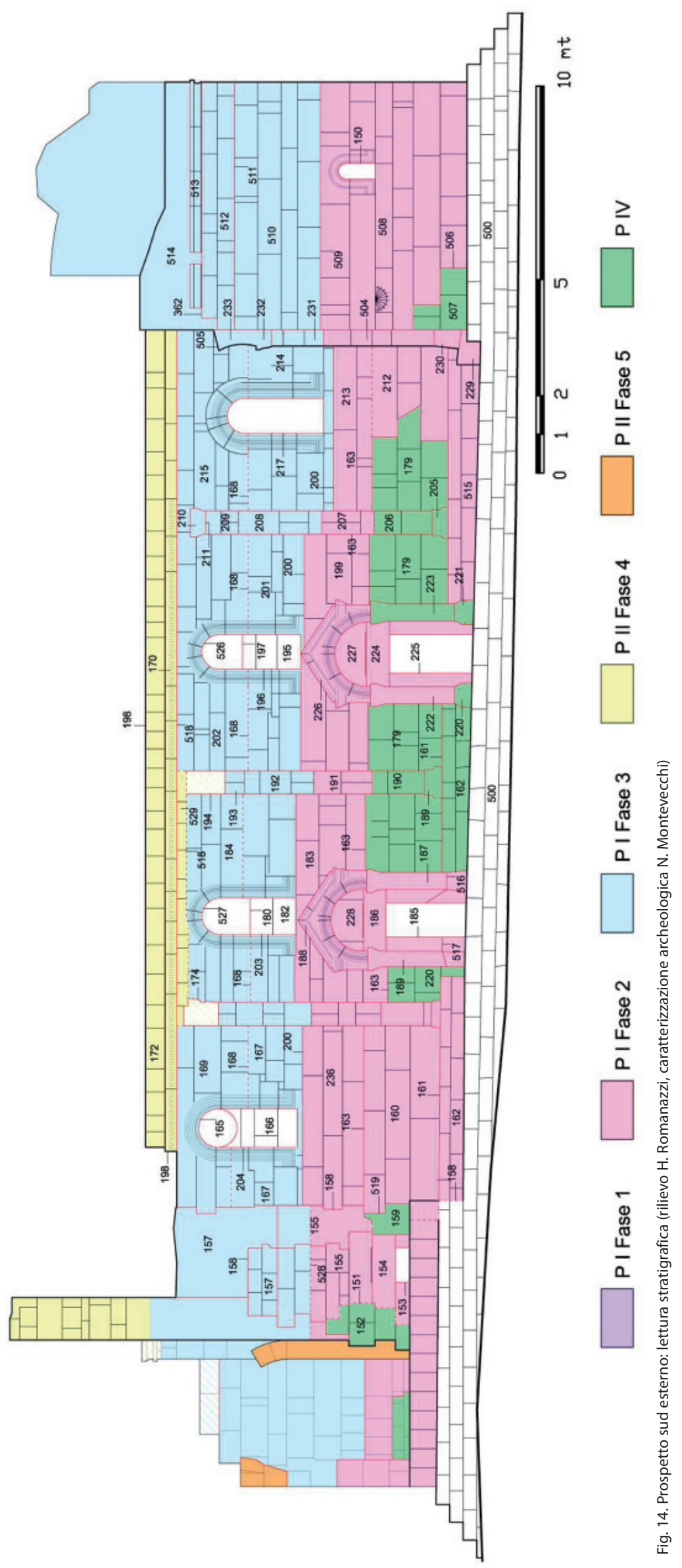


fronte sud della torre di nord-ovest le tracce dello smontaggio della muratura sopra l'arco.

Quanto al sistema di copertura del Periodo I, il crollo delle porzioni sommitali ed i rimaneggiamenti del successivo Periodo II, Fase 4, che comporta una riduzione delle altezze (si veda infra), non ci permettono con sicurezza di ricomporne la conformazione. Tuttavia una serie di elementi ci inducono a pensare che fosse concepito come un sistema a volte, con ogni probabilità del tipo a botte, con una serie di archi traversi innestati sulle paraste. La presenza delle paraste infatti, così come quella dei pilastri cruciformi, ci sembra ben ricollegabile a questa tipologia di copertura piuttosto che con la copertura a capriate chiamata più volte in causa negli studi pregressi su Ererouk, ma di fatto abbastanza estranea al panorama costruttivo della regione $^{26}$. Le volte a botte sono inoltre ben attestate in questa stessa Fase 3 a Ererouk: gli ambienti laterali del corpo dell'abside, come pure le torri del fronte ovest (Fig. 12) conservano la copertura a botte in conci attribuita alla Fase 3 del Periodo I.

Un sistema simile doveva essere stato concepito anche per gli ambienti esterni laterali nord e sud, con una arcata parallela ai fronti esterni, poggiante su paraste a est e ad ovest, definite nelle murature dei corpi in aggetto, e poi su colonne per il resto del fronte (Figg. 2, 12-13, 17) ${ }^{27}$.

L'evidenza mostra inoltre come la chiesa del Periodo I fosse stata concepita come un volume di maggiore altezza rispetto a quella del Periodo II: le coperture progettate per il porticato sud, con il sistema ad arcate descritto sopra, risultano molto più alte di quelle che si può supporre sulla base dell'altezza della cornice a dentelli US 170abbiano ad un certo momento ricoperto la adiacente navata laterale (Periodo II, Fase 4), e non sono dunque raccordabili con la loro ipotetica pendenza (Figg. 12-14). Tali coperture del portico risultano inoltre incompatibili con la presenza di una cornice a dentelli (US 170), che di fatto le taglia (Fig. 14): possiamo infatti osservare come l'inserimento della cornice preveda lo smontaggio delle arcate di ripartizione di direzione nord-sud del portico (US 174, 194, Fig. 14) ed una risistemazione del taglio con la posa in opera di un filare di conci di altezza molto contenuta (US 529), sulla quale va poi a poggiare la cornice a dentelli stessa (Figg. 12, 14).

\footnotetext{
${ }^{26}$ Si veda l'ampia discussione in Alpago-Novello 1977, pp. 18-22; Paboudjin 1977 , pp. 8-10.

${ }^{27}$ Sui numerosi rocchi di colonna rinvenuti in situ, si veda la descrizione di Marr, fornitaci in una traduzione di sintesi da G. Casnati. Alpago-Novello 1977, p. 22; Gandolfo 1982, p. 69.
}

Un altro indizio in tale senso è costituito dalla posizione della cornice a dentelli US 170 rispetto alle finestre, collocata proprio a ridosso della ghiera modanata di quella di sud-ovest (US 204, Figg. 14, 17): l'assenza di uno spazio di rispetto fra la copertura delle finestre e la cornice a dentelli ci induce a scartare l'ipotesi di una contestualità di queste componenti.

Il crollo totale delle coperture ed i rimaneggiamenti dei perimetrali intercorsi nel Periodo II non permette, almeno in questa fase iniziale dello studio, di stabilire con certezza se in questa Fase la chiesa fosse stata ultimata. Alcuni elementi ci inducono a considerare più probabile che un cambiamento del progetto sia intervenuto prima del completamento della fabbrica con la realizzazione delle coperture, forse determinato da difficoltà economiche o tecniche che ne hanno imposto un ridimensionamento. Infatti, l'interfaccia orizzontale riscontrabile sulla facciata ovest fra questa Fase 3 e la successiva Fase 4, Periodo II, e l'assenza di tracce interpretabili in funzione di un crollo sulla stessa facciata ci sembrano indicare che le coperture del Periodo I non siano state realizzate, e che il cantiere sia ripreso nel Periodo II introducendo significative modifiche al progetto iniziale (Figg. 9-11).

Possiamo però ricordare che almeno le arcate di partizione interna vennero costruite, come mostrano le porzioni in crollo conservate all'interno (Fig. 11). Nel porticato sud possiamo osservare come con ogni probabilità almeno le arcate vennero realizzate: la parasta est dell'arcata più esterna di direzione est-ovest conserva il concio di avvio dell'arco (US 505, Figg. 13-14), mentre sul fronte sud si vedono le tracce di uno smontaggio degli archi che poggiavano sulle paraste (US 174, 194, Figg. 14, 17). Non possiamo invece avere la certezza della messa in opera delle volte di copertura in quanto la rasatura intercorsa sui perimetrali sud e nord con la trasformazione del Periodo II, Fase 4, ne ha obliterato le tracce.

\section{Elementi cronologici}

Per quanto riguarda l'inquadramento cronologico della basilica del Periodo I, sia le iscrizioni presenti nella fabbrica che una serie di elementi architettonici decorativi hanno già in passato portato all'elaborazione di alcune ipotesi. In questa sede ne richiamiamo alcuni aspetti, soprattutto in relazione alle Fasi costruttive qui delineate.

Una inscrizione (Fig. 21) collocata nella parete esterna meridionale della struttura absidale (US 508, Fig. 14) costituisce un primo termine cronologico per la realizzazione delle strutture della Fase 2. Si tratta di una iscrizione 
in greco, su cinque linee e circoscritta entro una tabula ansata, che riporta la citazione del salmo 93:5 e che viene datata in letteratura a non oltre il VII secolo, ed è forse riferibile ad un orizzonte di V-VI secolo ${ }^{28}$. Le analisi più recenti sembrano avere stabilito come l'iscrizione sia stata realizzata precedentemente alla posa in opera, con la superficie da incidere in posizione orizzontale (Bessac c.s., 5.2.3): va pertanto a costituire un termine post-quem, visto che non abbiamo elementi che possano comprovare la contemporaneità della realizzazione dell' iscrizione rispetto al cantiere di costruzione della Fase 2.

Le altre iscrizioni sono incise sulle murature attribuite alla Fase 2, e dunque non possono che andare a costituire termini ante quem. Poiché queste murature vengono anche utilizzate nel Periodo II, è bene ricordare che la realizzazione di queste iscrizioni potrebbe anche essere intervenuta solamente nel Periodo II.

Una iscrizione è incisa sulla faccia ovest della parasta nord dell'abside (US 411, Figg. 3-4), ad altezza uomo: ricorda gli interventi di restauro promossi da un certo 'prete Yakob' che andarono ad interessare quello che viene definito un martyrium in onore di S. Giovanni Battista - quindi forse una parte specifica della chiesa; l'analisi epigrafica ha portato gli studiosi a collocarla fra VII ed il X secolo ${ }^{29}$.

L'altra è incisa sulla facciata sud (US 179, Figg. 14, 16-17), ad ovest del portale di sud-est, dal livello del capitello della colonna fino al livello dello pseudo- protiro: di commissione reale, ricorda un evento di cancellazione delle tasse e consente di associare il toponimo di Ererouk alla basilica; è datata al 1038 e la stessa data viene riportata anche sulla lunetta dello stesso portale di sud-est ${ }^{30}$.

Il contenuto delle iscrizioni non è particolarmente illuminante, ma è forse meglio compatibile con le fasi d'uso della basilica, e dunque riferirsi ad un periodo in cui questa fosse già stata completata; nell'ipotesi interpretativa qui formulata, questo si verifica solamente con il Periodo II. Non potendo tuttavia del tutto escludere la loro pertinenza al Periodo I, possiamo solo utilizzarle per affermare che certamente le strutture di questo Periodo I erano già state realizzate prima del X secolo (si veda anche infra, Periodo II, Elementi cronologici).

L'analisi delle componenti decorative condotta dagli specialisti di architettura armena, consolidatasi nella letteratura pregressa, può parimenti offrire alcuni elementi di inquadramento cronologico.

\footnotetext{
${ }^{28}$ Kouymjian 1977, p. 28; Greenwood 2004; Maranci 2005, pp. 5-6.

${ }^{29}$ Kouymjian 1977, p. 28; Gandolfo 1982, pp. 72-73.

${ }^{30}$ Kouymjian 1977, p. 28; ricorda anche che l'iscrizione venne identificata per la prima volta, documentata e pubblicata da Shakhatunian nel 1842.
}

La presenza della fascia modanata tutt'intorno agli stipiti e alla copertura delle aperture ha chiamato più volte in causa l'influenza di un gusto siriano ${ }^{31}$. Le modanature delle finestre che comprendono anche una fascia con dentelli, e cioè quelle del fronte ovest (Fase 2 e 3, Figg. 910, 15) e della finestra di sud-ovest (Fase 3, Figg. 14, 17) è stata definita 'inconsueta per l'ambiente armeno' ed attribuita al VI secolo ${ }^{32}$.

Se secondo Gandolfo gli pseudo-protiri (Fase 2, Figg. 16-17) rimandano alle chiese di Tekor (Cuneo 1988, pp. 642-644) e K'asal (Aparan: Cuneo 1988, pp. 168-169), della fine del $\mathrm{V}$ secolo, alcuni elementi, come l'uso delle semi-colonne e delle basi ad anello, potrebbero collocarsi in un periodo successivo, visto che si ritrovano nella chiesa di Avan, posteriore al 590 (Gandolfo 1982, p. 73).

Il gruppo di capitelli del corpo absidale (i capitelli su cui si imposta il catino dell'abside e delle absidiole laterali, il capitello della parasta nord che si affianca all'abside ${ }^{33}$ ed il capitello della parasta che si affianca a sud all'absidiola laterale sud: Fase 3, Figg. 3, 13) costituiscono secondo Gandolfo un gruppo stilisticamente omogeneo che rimanda al VI secolo (Gandolfo 1982, pp. 75-76) ${ }^{34}$.

Infine, non ci sembra proficuo, in questa fase degli studi, riferirsi per la datazione a modelli specifici di impianto architettonico, in quanto ci sembra che il dibattito risulti ancora aperto per molti versi; il rischio è quello di innescare un modello deduttivo ad andamento circolare privo di solide basi e di scarsa utilità.

Ricordiamo solamente in questa sede come gli studi pregressi abbiano sottolineato l'analogia con la tradizione architettonica siriana soprattutto per la presenza delle torri in facciata, come le chiese di Qalb Loze, Rowayha e Soleib, attribuite al V secolo ${ }^{35}$; l'influenza siriana si riscontrerebbe anche nella decorazione delle aperture che prevedono una modanatura lungo lo stipite intero e non limitata alla copertura, come occorrerebbe invece tradizionalmente nelle chiese armene (Gandolfo 1982, p. 73). A questo

\footnotetext{
${ }^{31}$ Si vedano ad esempio Alpago-Novello 1977, pp. 22-23; Gandolfo 1982, p. 73. 32 Gandolfo 1982, p. 73, accosta questa decorazione a quella presente sull'architrave di uno dei portali della basilica di Elvard, datata al VII secolo (Cuneo 1988, p. 163), ma per lo stile la vede piuttosto riferibile al VI secolo: Gandolfo 1982, p. 73. Ancora ad Elvard si rimanda per la decorazione modanata delle restanti finestre del fronte meridionale (qui attribuite alla Fase 3), ma anche di quelle dell'abside (qui attribuite alle Fasi 2 e 3): Gandolfo 1982, pp. 73-74.

33 Il capitello sulla parasta che affianca l'abside a sud, invece, è accostato da Gandolfo ad un capitello della chiesa di Putni del VII secolo: Gandolfo 1982, p. 75.

${ }^{34}$ Per quel che riguarda la cornice marcapiano del corpo absidale (Attività 15, Fase 3), Gandolfo tenderebbe a collocarla fra IX e X (Gandolfo 1982, pp. 72 73), datazione in apparente contrasto con quella dei capitelli, a meno che non si voglia pensare ad un massiccio quanto poco verosimile reimpiego degli stessi.

${ }_{35}$ Paboudjin 1977, pp. 8-10; Alpago-Novello 1977.
} 


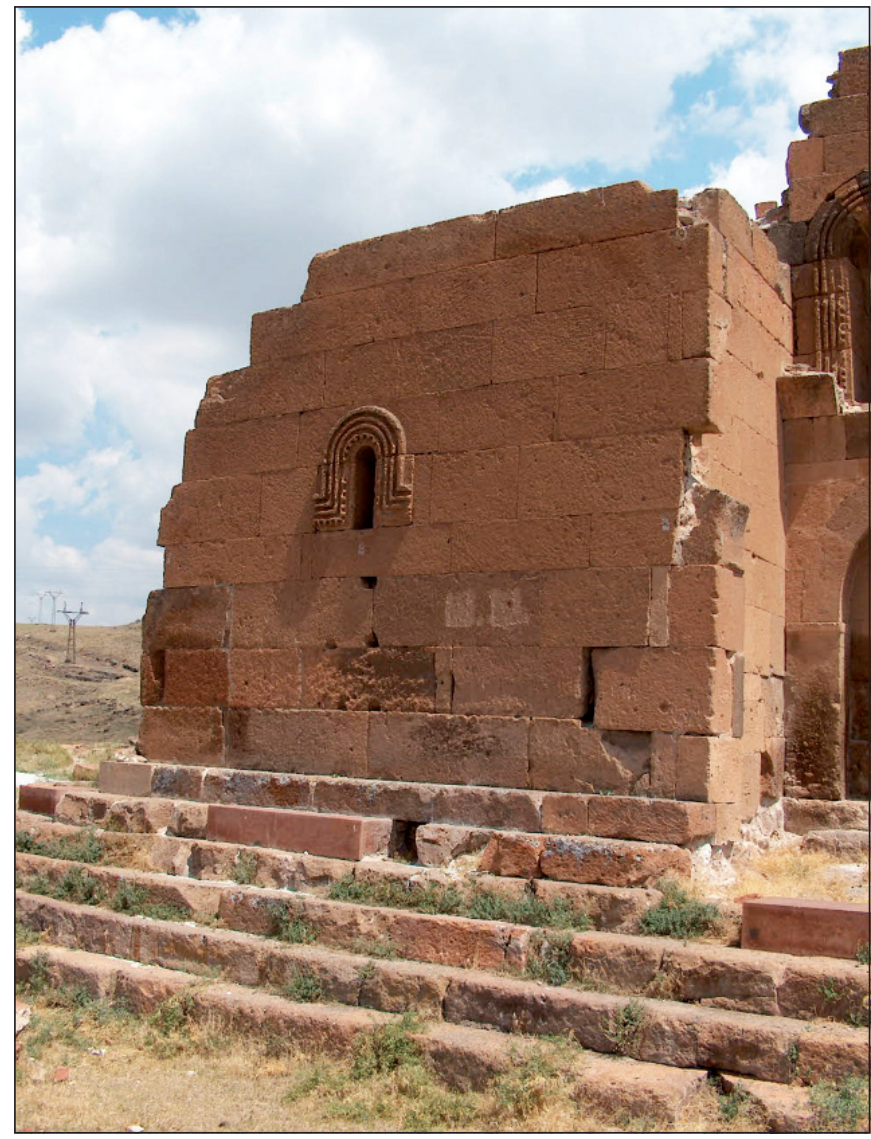

Fig. 15. La torre di nord-ovest, da sud-ovest (Foto C. Tonghini)

proposito, dunque, il contributo dell'analisi stratigrafica condotta nel 2005 consiste nell'avere stabilito che la chiesa del Periodo I, almeno per quel che riguarda le Fasi 2 e 3, nasce indubbiamente con un impianto che già prevede gli avancorpi di facciata.

In conclusione, le iscrizioni, gli elementi stilistici e l'eco di modelli siriani sembrano puntare ad una collocazione della fondazione della chiesa, e dunque ad una datazione del Periodo I, nell'ambito del VI, con una possibile estensione al VII secolo; non disponiamo invece a tutt'oggi di nessun elemento, nemmeno derivato dalla fonte scritta, che possa chiarire la natura dell'interruzione dei lavori del cantiere del Periodo I e definirne i limiti cronologici.

\section{Periodo II}

Il Periodo II inquadra interventi di trasformazione dei volumi della chiesa.

Lo stato di conservazione della struttura rende certo difficile una chiara individuazione e interpretazione delle cause che hanno condotto alla elaborazione di un progetto di modifica in questo Periodo; tuttavia, l'assenza in facciata

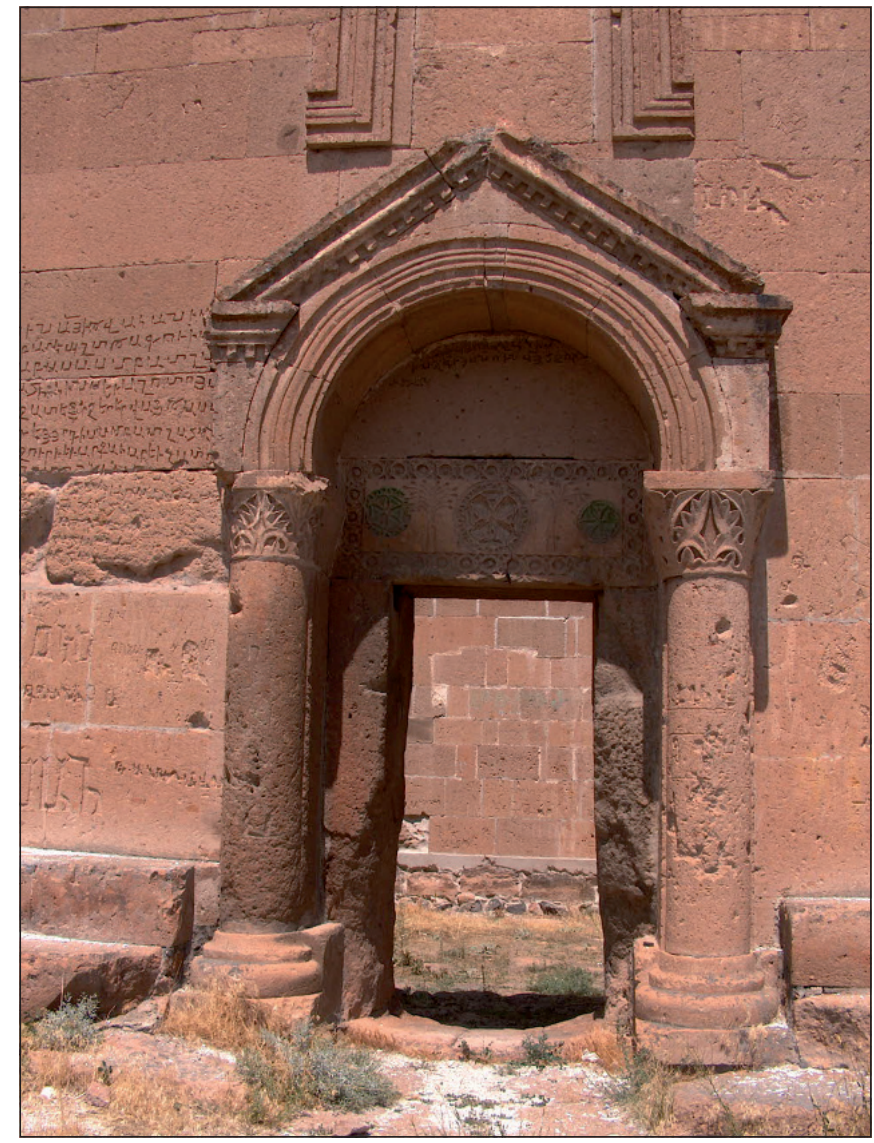

Fig. 16. II portale US 225, da sud (Foto C. Tonghini)

di tracce di crollo e distruzione, così come l'andamento orizzontale dell'interfaccia fra la Fase 3 e la Fase 4, rendono verosimile una loro interpretazione come una fase di modifica al progetto originale, intervenuta nel corso dei lavori, piuttosto che di un restauro resosi necessario di seguito ad un crollo.

In questo Periodo II viene ribassato il fronte sud della fabbrica, ed una analoga modifica potrebbe avere interessato il fronte nord. Sulla facciata ovest la costruzione della facciata prosegue andando a definire un cleristorio ${ }^{36}$. Vengono infine realizzate le coperture, utilizzando in parte il sistema di arcate del Periodo precedente: la linea di imposta degli archi è la stessa del Periodo I, ma allora era previsto che gli archi si sviluppassero per una maggiore altezza. I precedenti sistemi di copertura dei portici nord e sud vengono demoliti, mentre viene apportata una sostanziale modifica a quello del fronte ovest ${ }^{37}$.

${ }^{36}$ E' possibile che una simile configurazione fosse anche prevista nel progetto del Periodo I, ma le modifiche apportate alle murature del Periodo I nel successivo Periodo II non hanno lasciato tracce che possano guidare l'interpretazione in tale senso.

${ }^{37}$ L'ipotesi che sia il cleristorio che la costruzione del portico siano frutto di una fase di rimaneggiamento successiva a quella originale è già stata avanzata da altri 


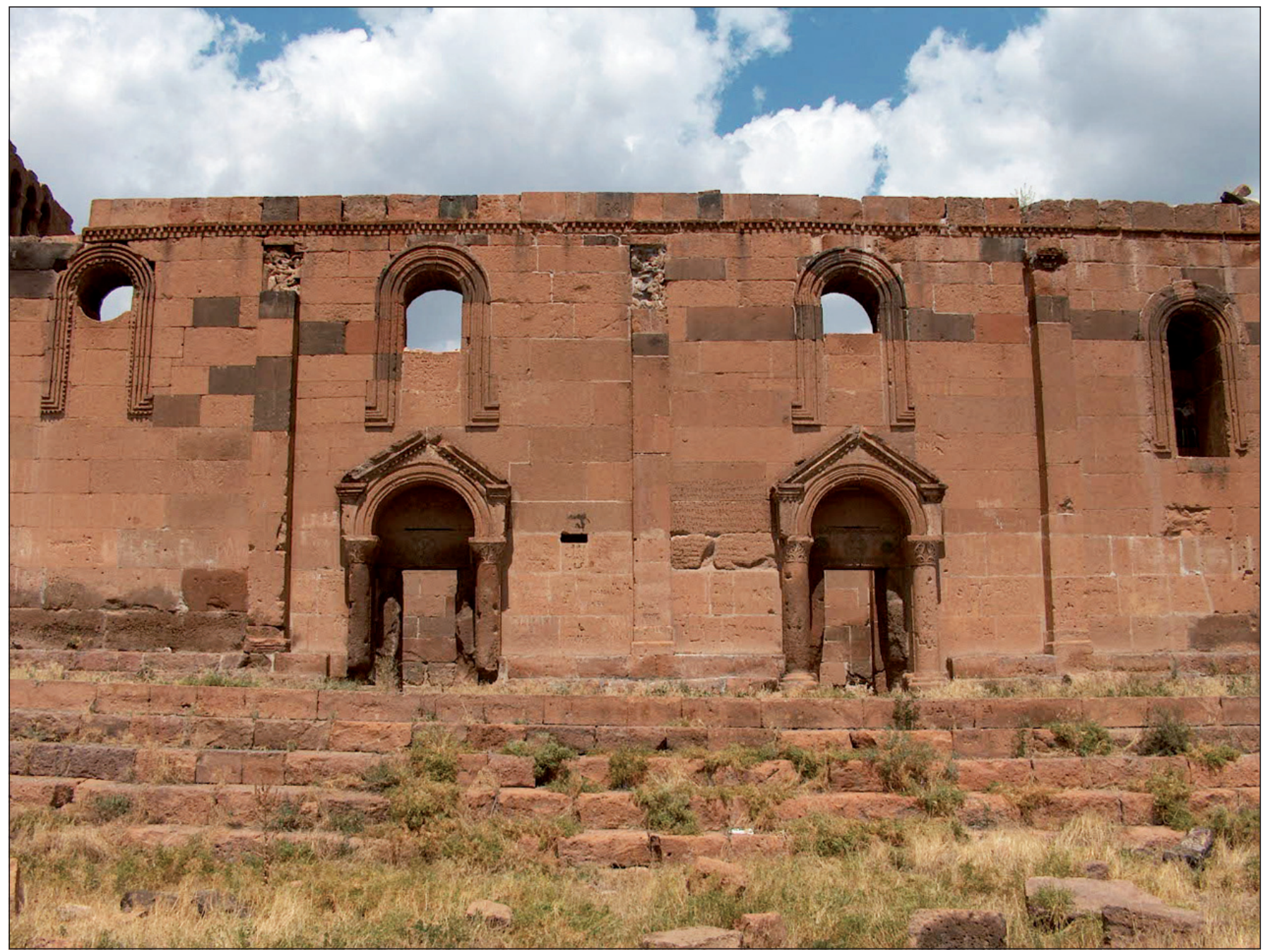

Fig. 17. Le finestre del fronte sud, da sud (Foto C. Tonghini)

Fase 4 (Figg. 4, 10, 14, 17, colore giallo)

Attività 22: ripresa della costruzione della facciata ovest, con cleristorio e trifora (Figg. 9-12, 14, 19);

Attività 23: abbassamento del fronte sud, con smontaggio delle arcate traverse, ed inserimento di una cornice a dentelli (US 170) (Figg. 12-14, 17);

Attività 24: risistemazione del fronte nord;

Attività 25: copertura della chiesa.

Abbiamo riferito ad un diverso periodo (Periodo II) una serie di attività che vanno chiaramente a modificare le altezze dei volumi e le coperture previste nel progetto originale del Periodo I.

Viene realizzata la porzione superiore della facciata ovest (US 35, Fig. 10) e delle pareti di sopraelevazione autori, come ad esempio Paboudjian 1977, p. 8; Gandolfo 1982, p. 71 e nota 338. della navata centrale (cleristorio), di cui rimane l'angolata sud-ovest e l'avvio della parete meridionale (Attività 18: Figg. 9-12, 14, 19). La muratura, ben conservata nella sola facciata ovest e costruita con materiale che sembra essere in parte di recupero ${ }^{38}$, risulta tipologicamente ben distinta da quella sottostante (Figg. 9, 11). Che si tratti di un diverso progetto costruttivo rispetto a quello portato avanti nel Precedente Periodo I lo mostra il fatto che l'interfaccia (US 34) con la precedente Fase 3, Periodo I, corrisponda esattamente con la terminazione delle paraste del fronte esterno (Fig. 10), e che la muratura di questa Fase 4 al di sopra delle suddette paraste non rechi alcuna traccia riferibile al crollo o allo smontaggio delle strutture che queste paraste erano state progettate a portare (US 35, Figg. 9-11).

\footnotetext{
${ }^{38}$ Questo aspetto è confermato nell'analisi di Bessac: Bessac c.s., 5.5.7.
} 


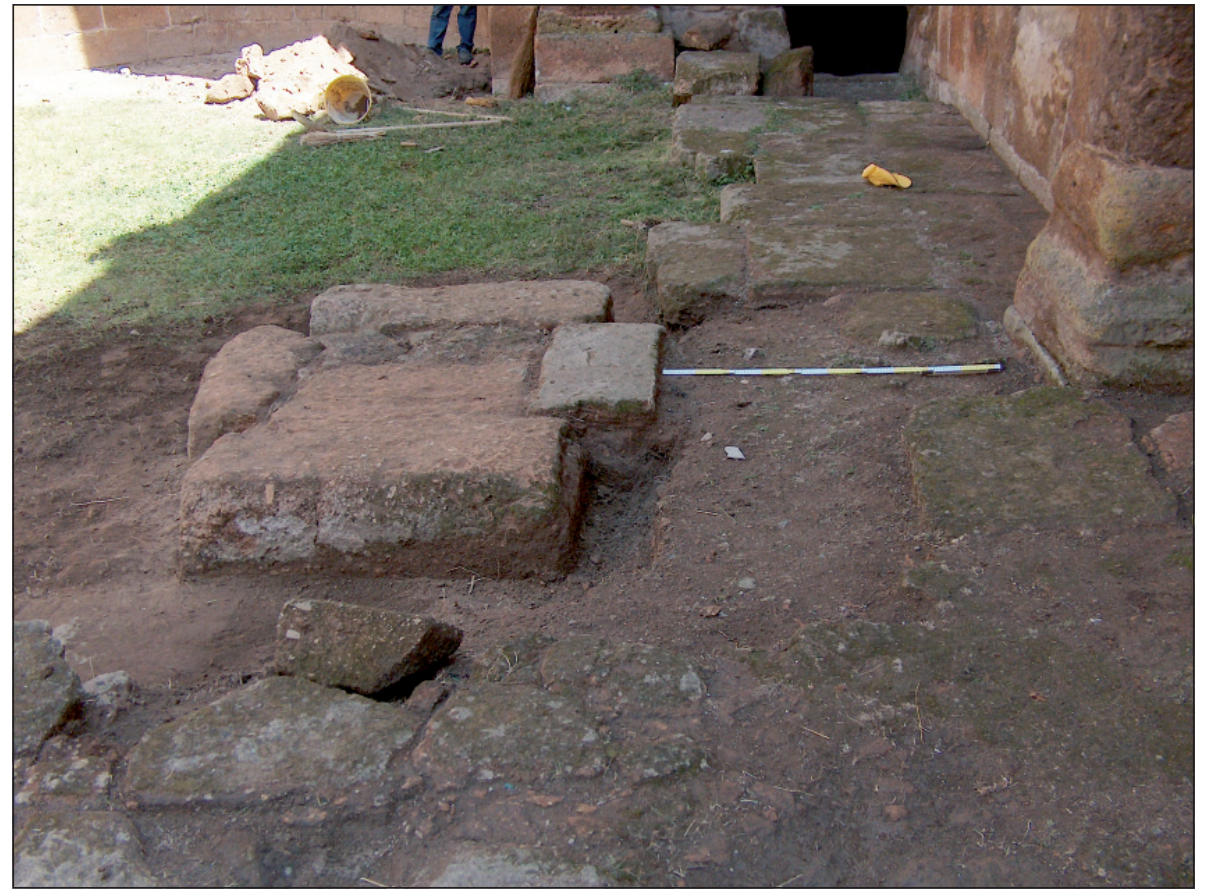

Fig. 18. II pilastro cruciforme di sud-est, da ovest (Foto C. Tonghini)
Sul fronte sud, all'esterno, vengono apportate delle modifiche interpretabili in funzione di un abbassamento dei volumi interni adiacenti e della conseguente eliminazione della copertura del portico. Vengono smontati gli archi traversi che costituivano la nervatura del sistema di copertura del portico (US 174, 194, Fig. 14), impostati sulle paraste del fronte sud, e anche le arcate più esterne che poggiavano sulle paraste di testata est e ovest, addossate ai corpi in aggetto dell'abside (US 505, Figg. 2, 14) e della porzione ovest: la pendenza della copertura del portico sud prevista dal progetto originale del Periodo I, che si può evincere dall'altezza delle paraste e dalle porzioni superstiti degli archi (ad esempio US 505), risulta incompatibile con la cornice a dentelli (US 170) visibile oggi e dunque con la copertura della navata interna laterale (Fig. 14). Le tracce di questa operazione di modifica sono visibili sul fronte sud, al di sopra delle paraste: un corso piuttosto sottile (US 529) va a regolarizzare l'area dalla quale era stato smontato l'avvio dell'arco (US 174, 194), e su questo corso viene sistemata una cornice con decorazione a dentelli (US 170, Fig. 14); la posizione di questa cornice è totalmente incompatibile con la copertura del portico progettata nel Periodo I in appoggio alle paraste ${ }^{39}$. Inoltre, questi due corsi, quello più sottile (US 529) e

39 Si veda Paboudjin 1977, che riporta fra le varie interpretazioni quella di Thoramanian che collega la posa in opera della cornice a dentelli «all'esigenza di mascherare i danni alle opere murarie in seguito alla soppressione dei porticati», p. 8 . quello con la cornice a dentelli (US 170), sono posizionati a ridosso dell'estradosso della finestra US 204 (Fig. 14); questo elemento ci sembra ben interpretabile in funzione di un rimaneggiamento di questo fronte in quanto sembra andare ad obliterare un intervallo - quello fra il completamento delle finestre e l'imposta delle coperture - essenziale alla composizione armonica fra le parti e generalmente ampiamente rispettato nelle architetture della regione.

La cornice a dentelli del lato sud (US 170), dunque, è incompatibile con l'altezza originale del portico del Periodo I e questa altezza, a sua volta, poteva raccordarsi solo con un sistema di coperture delle navatelle laterali più alto rispetto a quello che venne poi realizzato nel Periodo II.

Una analoga operazione di riduzione dell'altezza del perimetrale deve avere interessato il fronte nord: l'ultimo corso visibile oggi, infatti (US 172, Fig. 14), è realizzato con materiale di diverso taglio e pezzatura rispetto alle murature della precedente Fase 3.

Per la copertura degli interni si continua a sfruttare l'ossatura del sistema messo a punto nel periodo precedente, con le paraste che servivano da appoggio agli archi traversi (Fig. 2); i nuovi archi trasversali della navatelle laterali, tuttavia, pur utilizzando lo stesso livello di imposta, vengono costruiti (o parzialmente ricostruiti) ad un'altezza inferiore rispetto a quella prevista nel progetto originale del Periodo I. Con ogni probabilità vengono riutilizzate solamente le due arcate di partizione interna fra le navate: su queste vanno ad impostarsi le murature di partizione, $\mathrm{i}$ 


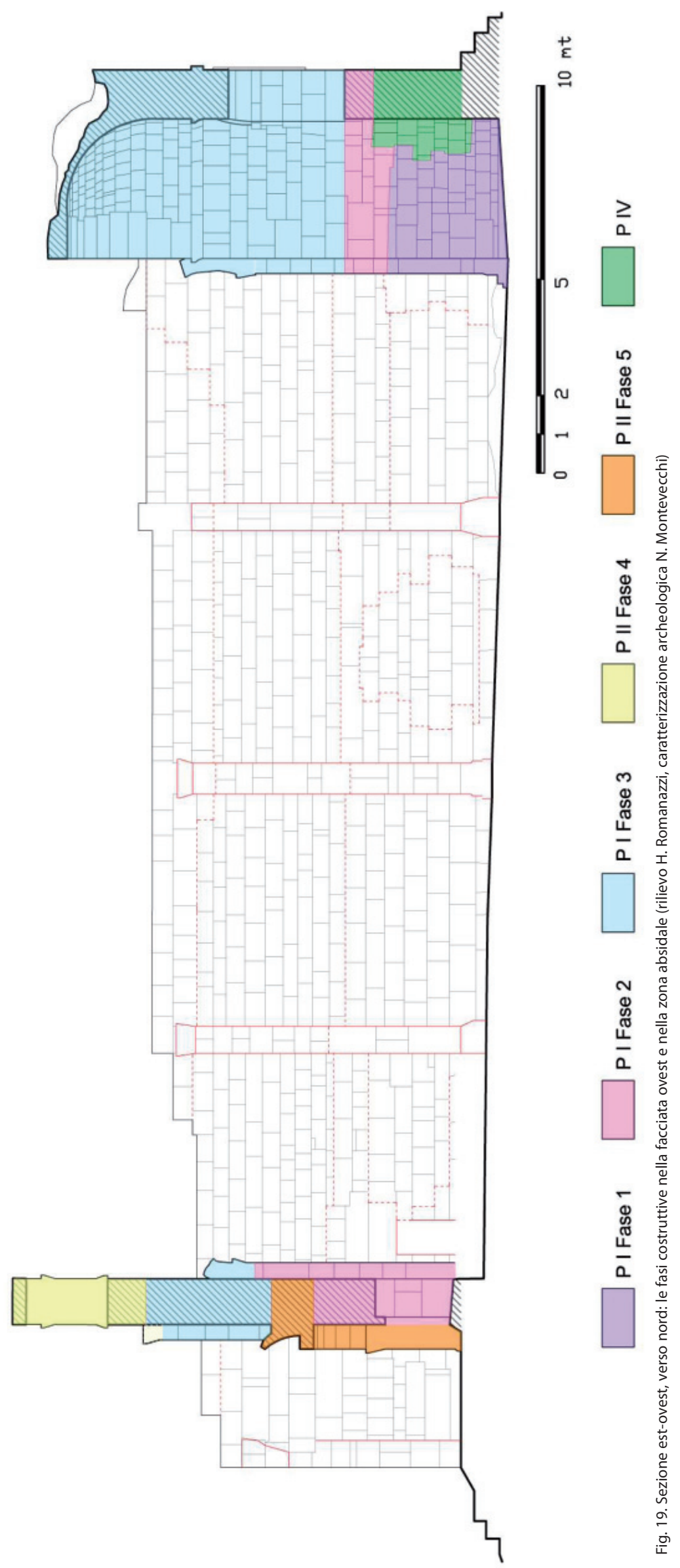


cui lacerti sono ancora ben visibili sul fronte ovest interno (Figg. 2-4, 11). E' di nuovo l'obliterazione della copertura del portico (US 174, 194, Fig. 14) e l'altezza della cornice a dentelli del lato sud (US 170, Fig. 14) che ci forniscono indicazioni a riguardo, e che ci suggeriscono una diversa impostazione dell'altezza delle coperture delle navate interne laterali. Volte a botte impostate sui perimetrali e sui muri di partizione interna andavano a coprire le navate laterali. Un indizio sulle volte a botte in conci delle navate laterali si può ricavare dalle osservazioni riportate da Strzygowski nel corso della sua ricognizione e riprese da Gandolfo: Strzygowski identifica nell'angolo interno nord-est tre pietre collocate sopra la parete settentrionale interpretabili come gli elementi superstiti dei conci di una botte; parallelamente, sul muro est, era collocata una pietra con un profilo che si raccordava con quello dell'arco descritto dalla botte; le pietre sarebbero anche documentate in vecchie fotografie ${ }^{40}$.

Lo stato di conservazione delle strutture non permette di stabilire il tipo di copertura della navata centrale, ma, in considerazione del sistema messo in opera nelle navate laterali e negli ambienti adiacenti, e delle tradizioni costruttive regionali ${ }^{41}$, è assai verosimilmente realizzato con volte a botte in conci.

Fase 5 (Figg. 10, 14, 19, colore arancione)

Attività 26: costruzione del nuovo portico, con modifica al sistema di paraste originali.

A questo Periodo II si riferisce anche la costruzione di un portico addossato alla facciata ovest (Fase 5, Attività 26, Figg. 10, 14). Tale intervento potrebbe essere stato realizzato contemporaneamente a quello descritto nella precedente Fase 4, ma, in considerazione dell'interruzione dei rapporti stratigrafici fra le parti intercorsa con i crolli si è preferito riferirla ad una diversa Fase.

In appoggio alla facciata ovest (Fig. 20) viene costruita una muratura ritmata da arcate (US 42, 46, Fig. 10), pressoché interamente conservata, con funzione di sostegno della volte a botte di copertura dello spazio antistante (Figg. 2, 9-10, 12, 14, 19-20). Tale struttura viene ammorsata unicamente alle due paraste costruite nella Fase 2, Periodo I (US 18, 20), in buona parte smontate a questo fine (Fig. 10). Anche lo pseudo protiro del portale centrale viene smontato per adattarsi alla nuova altezza della volta.

${ }^{40}$ Gandolfo 1982, p. 68, e note 320 e 321; prima di lui Paboudjin 1977, pp. 89 e nota 45.

${ }^{41}$ Per le diverse interpretazioni ed una discussione dettagliata, si vedano AlpagoNovello 1977, pp. 18-22; Paboudjin 1977, pp. 8-10.

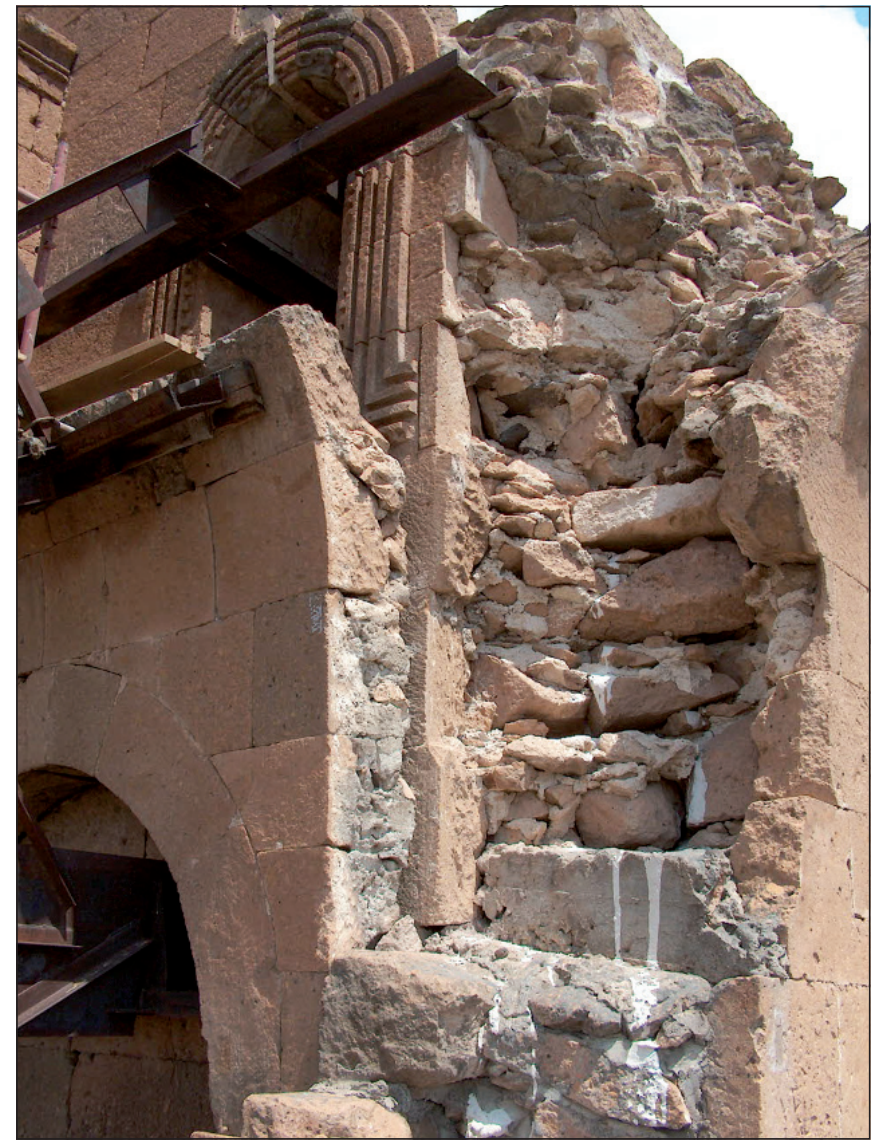

Fig. 20. Angolo sud-ovest della facciata, con sezione a vista della muratura del Periodo I, Fase 2 e Fase 3, ed il portico del Periodo II, Fase 5. Da ovest (Foto C. Tonghini)

La volta a botte, di direzione nord-sud, andava ad appoggiarsi ad ovest ad una arcata costruita a filo delle torri laterali ed impostata sulle paraste, parzialmente smontate e risistemate, già definite nel Periodo I (Figg. 2, 10, 14-15). Di questa parete si conserva in elevato l'innesto della prima arcata inserita in rottura nella parasta sudovest della torre settentrionale. Non ci sono elementi per stabilire come si articolasse questa arcata, e se gli archi poggiassero su colonne.

La volta che va a coprire il nuovo portico va in parte ad obliterare le due grandi finestre del fronte ovest (Figg. 9, 20). Il crollo delle porzioni sommitali non consente di comprendere appieno la configurazione del fronte ovest in questo Periodo, ed in particolare come fosse organizzato il raccordo fra il nuovo portico e gli avancorpi.

\section{Elementi cronologici}

Non disponiamo al momento attuale di elementi che ci consentano di riferire questo Periodo ad un arco cronologico ben definito, anche e soprattutto in merito all'interruzione ed alla ripresa dei lavori. Tuttavia, in considerazione 
delle forti analogie fra le strutture dei Periodi I e II, è assai probabile che il Periodo II vada collocato in prossimità del Periodo I.

La presenza del cleristorio caratterizza la fabbrica del Periodo II, ma sulla base dell'evidenza conservatasi non possiamo escludere che anche il progetto del Periodo I potesse avere previsto una componente simile. Questo cleristorio è stato considerato da vari studiosi come un elemento alquanto inusuale nel panorama dell'architettura armena, tanto da chiamare in causa influenze ellenistiche e siriane (Gandolfo 1982, p. 68; Paboudjian 1977, pp. 10, 13); la datazione di una sua introduzione nel panorama armeno rimane alquanto incerta. Allo stato attuale delle conoscenze, pertanto, non è possibile conferire una valenza cronologica a questa componente.

Due delle iscrizioni discusse più sopra (Periodo I, Elementi cronologici), incise una sulla parete ovest dell'abside interna (US 411, Fig. 3) e l'altra sulla parete esterna sud (US 179, Figg. 16-17) potrebbero essere state realizzate tanto nel Periodo I quanto in questo Periodo II: si tratta infatti di interventi apportati alle murature costruite certo nel Periodo I, ma che continuano a costituire i perimetrali della chiesa del Periodo II. Il testo delle iscrizioni non è particolarmente illuminante, ma è certo meglio compatibile con il contesto di una chiesa ormai completata. In considerazione del fatto che abbiamo ipotizzato il completamento della chiesa solamente nel Periodo II, è possibile che il termine ante quem che le due iscrizioni definiscono, i secoli VII-X la prima e il 1038 la seconda, possa essere utile ad orientare il Periodo II e suggerire che la chiesa del Periodo II dovesse essere stata completata fra VII-X secolo, e certamente prima del 1038. In considerazione della forte analogia che si riscontra fra il Periodo I ed il Periodo II in merito a forme e tecniche costruttive e alla tipologia del materiale impiegato non è inverosimile che il suo completamento vada a collocarsi già nel VII secolo; solo l'acquisizione di nuovi dati permetterà in futuro di meglio definire il quadro cronologico.

Quanto agli elementi decorativi, gli unici che possiamo certamente riferire a questo Periodo II consistono essenzialmente nella cornice a dentelli della facciata esterna sud (US 170, Fig. 17), peraltro non troppo diversa dalle cornici a dentelli che decorano le absidi (Figg. 3, 13) o i timpani degli pseudo-protiri del Periodo I (Figg. 9, 16-17), e ci sembra dunque un elemento troppo fragile a supporto di una particolare datazione ${ }^{42}$.

\footnotetext{
${ }^{42} \mathrm{Si}$ veda comunque a questo proposito Gandolfo 1982, p. 74
}

\section{Attività non fasizzabili}

Attività 27: parziale riduzione della luce di tre finestre del fronte sud e loro trasformazione in aperture ad oculo (Figg. 14, 17).

In una Fase che non è possibile al momento attuale inserire nella sequenza elaborata fino a qui si è proceduto alla parziale riduzione della luce di tre delle quattro finestre del fronte sud con la realizzazione di una muratura di tamponamento (US 166, 182, 195, Fig. 14) che va a definire delle nuove aperture ad oculo (US 165, Figg. 14, 17). L'accuratezza dell'intervento, ben rilevabile soprattutto sul fronte esterno, e la tipologia del materiale impiegato (litotipo, finitura) non sembrano discostarsi dai caratteri costruttivi e tipologici rilevati nei Periodi I e II, e non ci sono elementi per riferirli ad un Periodo piuttosto che all'altro. In mancanza di altri elementi, ricavabili forse dall'analisi delle malte di allettamento, abbiamo preferito non forzare l'interpretazione accostandoli ad una delle Fasi descritte in precedenza.

\section{Periodo III}

Questo Periodo si riferisce al lungo abbandono che ha portato alla trasformazione dell'edificio in rudere. Difficilmente inquadrabile dal punto di vista cronologico, il momento dell'abbandono potrebbe collocarsi in un ampio arco di tempo che potremmo circoscrivere fra l'ultimo riferimento al sito di Ererouk attestato nelle fonti scritte, databile al 1208-1212 43 , e le prima segnalazioni dei resti della basilica ad opera di viaggiatori e studiosi a partire dalla metà del XIX secolo ${ }^{44}$.

Periodo IV (Figg. 4, 8, 14, 19, colore verde)

Con i primi studi, prende anche il via la stagione degli interventi mirati al consolidamento delle strutture in crollo, ed alla parziale risarcitura delle lacune; questi primi interventi sono realizzati nel 1928, 1948, ed infine 1957$1959^{45}$. Alcuni di questi interventi sono riportati sui prospetti qui pubblicati.

A partire dal 2002, sotto la direzione dell'arc. Casnati, ha preso il via un nuovo progetto, comprendente anche

\footnotetext{
${ }^{43}$ Kouymjian 1977, p. 28: si tratta di un'iscrizione identificata nella chiesa di S. Giovanni, Ani, che ricorda Ererouk.

${ }^{44} \mathrm{Si}$ veda l'accurata lista redatta in Kouymjian 1977, p. 28: la prima descrizione dell'edificio, del 1842, si deve a H Shakhhatounian. Kouymjian 1977, p. 28, ricorda anche che Marr menziona iscrizioni greche del periodo 1600-1700 redatte forse da viaggiatori occidentali.

${ }^{45}$ Per un elenco ed una descrizione degli interventi, si vedano Kouymjian 1977 , p. 28; Cuneo 1988, p. 234. Per il periodo più recente, si veda infra, Introduzione. ${ }^{46}$ Le osservazioni di Strzygowski sono riportate e discusse in Paboudjin 1977, pp. 8-9 e nota 45; Gandolfo 1982, p. 68, e note 320 e 321.
} 
un programma di consolidamento e restauro (Casnati 2005), nell'ambito del quale si sono collocate le indagine archeologiche oggetto di questo studio (si veda infra, Introduzione).

\section{CONCLUSIONI}

I risultati dell'analisi archeologica qui presentati e discussi hanno permesso di formulare una serie di ipotesi sulle vicende costruttive che hanno interessato la basilica di Ererouk. Queste ipotesi si fondano sugli elementi emersi nel corso delle indagini condotte sul campo nell'agosto del 2005 e necessitano naturalmente di un approfondimento ed ampliamento delle indagini per potersi trasformare in proposte interpretative più solide.

Tuttavia ci sembra che l'approccio stratigrafico abbia consentito di gettare le basi per la ricomposizione della storia costruttiva della basilica di Ererouk, e fissato i caratteri delle varie Fasi e Periodi che la scandiscono.

Nelle righe che seguono vengono sintetizzati i passaggi principali della sequenza costruttiva e delle ipotesi elaborate, già discussi in dettaglio nei paragrafi descrittivi di Fasi e Periodi.

Come si è visto, i dati raccolti indicano che già a partire dal Periodo I viene progettata e realizzata una chiesa che sviluppa in pianta tutte le componenti che caratterizzano l'edificio attuale: una basilica a tre navate, orientata estovest e collocata su uno stilobate a gradoni, con un corpo absidale corredato di due vani laterali che aggettano sui lati nord e sud e due corpi parimenti aggettanti che inquadrano la facciata ovest; la chiesa è provvista già in questa fase redazionale di portici sui lati sud, ovest e nord.

L'evidenza esaminata porta a sottolineare come il cantiere del Periodo I sia stato più volte interrotto per ragioni riconducibili a problemi strutturali e all'organizzazione logistica del cantiere (messa in opera delle aperture, avvicendamento delle maestranze e delle stagioni, approvvigionamento del materiale), ma che potrebbero essere connesse anche ad eventi storici ad oggi non meglio configurabili. Nella Fase 1 viene impostato un edificio che segue lo stesso andamento planimetrico dell'edificio attuale nell'area absidale, nella definizione degli ambienti laterali, e nei perimetrali nord e sud, compresa la messa in opera delle paraste interne dei fronti sud e nord, mentre è solo ipotizzabile nella porzione ovest dell'edificio (Figg. 2, 4, 19). Questo primo edificio è interessato da un fenomeno di cedimento fondale, rilevabile nei paramenti interni dell'abside e degli ambienti adiacenti, che comporta una prima interruzione dei lavori e l'introduzione di misure correttive con l'avvio della Fase 2. In questa Fase 2 viene ripreso il dissesto del corpo absidale sul fronte interno e ricostruita l'intera parete esterna (Attività 6$)$, costruite la porzione inferiore e mediana delle pareti perimetrali sud e nord (Attività 7-8) e realizzata la corrispondente porzione della facciata ovest e delle torri laterali (Attività 9, Figg. 9-11, 14-15). Vengono inoltre realizzati i portali sovrastati da pseudo-protiri della facciata sud, così come quello della facciata ovest; anche una serie di aperture vengono definite nel corpo absidale: due finestre nell'ambiente sud, una sul lato sud (Fig. 13) ed una sul lato est; due finestre nell'ambiente nord del corpo absidale affacciate ad est (Fig. 7).

L'avanzamento del cantiere della Fase 2 conosce quindi una interruzione, verosimilmente in vista della definizione delle aperture sui lati ovest e sud (Attività 11). L'andamento piuttosto regolare ed orizzontale dell'interfaccia (Fig. 14) e il legame costruttivo che si riscontra anche a questo livello fra la facciata ovest e gli avancorpi ovest (Fig. 9), e fra l'avancorpo di sud-ovest ed il fronte sud (Fig. 12) portano infatti a mettere in relazione l'interruzione e la ripresa con l'organizzazione del cantiere piuttosto che configurarla come una operazione di ricostruzione che fa seguito ad un evento distruttivo. Nessuna modifica sembra venire apportata all'articolazione planimetrica dell'edificio nella Fase 3: si procede al completamento dei fronti sud, ovest e nord, con due finestre che si aprono a ovest (Figg. 9-10) e quattro a sud (Figg. 14, 17), mentre il fronte nord rimane cieco; vengono anche realizzate le aperture degli avancorpi ovest, di cui rimangono solo quelle dell'ambiente di nord-ovest (Figg. 10, 15). Sui lati nord, ovest e sud proseguono i lavori per la definizione dei porticati coperti. Vengono realizzate le coperture delle torri ovest e degli ambienti adiacenti l'abside, e costruiti i catini dell'abside e delle absidiole laterali (Figg. 3-4, 7-8, 13-14, 19). Vengono quindi definite le strutture di partizione interna delle navate, con la messa in opera delle arcate impostate sulle paraste di testata ad est e a ovest (Attività 18, Figg. 3-4,11) e su una serie di pilastri cruciformi che suddividono la pianta in tre navate (Attività 17, Figg. 2, 18). Gli interventi del successivo Periodo II così come il crollo delle porzioni sommitali e delle coperture hanno obliterato le tracce relative all'eventuale costruzione delle murature di partizione impostate sulle arcate e al completamento delle coperture (Fig. 11); tuttavia una serie di elementi (in particolare nel porticato sud) ci ha portato a concludere che la chiesa del Periodo I fosse stata concepita come un volume di altezza maggiore rispetto a quella del Periodo II.

I dati raccolti ci hanno portato ad ipotizzare che la chiesa del Periodo I non sia mai stata davvero completata 
fino al livello delle coperture, ma che sia intervenuto un cambiamento di progetto (Periodo II). Sulla facciata ovest, l'andamento orizzontale dell'interfaccia fra la Fase 3, Periodo I, e la successiva Fase 4, Periodo II, e l'assenza sulla stessa facciata di tracce interpretabili in funzione di un crollo ci ha indotto a ritenere che il cantiere della Fase 3 si sia arrestato prima del completamento della fabbrica con la realizzazione delle coperture. Non sono però emersi elementi sufficienti che permettano di ipotizzare le ragioni di questa interruzione e del cambiamento di progetto: difficoltà economiche o tecniche, così come mutamenti storico-politici ancora da inquadrare potrebbero stare alla base del ridimensionamento del progetto.

Nel Periodo II vengono ribassati i fronti sud e nord, mentre sulla facciata ovest viene definito un cleristorio; vengono infine realizzate le coperture, impiegando in parte il sistema impostato nel precedente periodo, ma con una riduzione delle altezze previste nel progetto originale del Periodo I, la demolizione delle coperture dei porticati nord e sud e una sostanziale modifica del porticato ovest.

Nella Fase 4, sul fronte sud, all'esterno, vengono apportate delle modifiche interpretabili in funzione di un abbassamento dei volumi interni adiacenti e della conseguente eliminazione della copertura del portico: vengono smontati gli archi traversi che costituivano nel Periodo I la nervatura del sistema di copertura del portico (Fig. 14), impostati sulle paraste del fronte sud, e le arcate più esterne che poggiavano sulle paraste di testata est e ovest; la risistemazione del fronte sud dopo lo smontaggio comporta anche l'inserimento di una cornice con decorazione a dentelli (Fig. 14).

Per la copertura degli interni si continua a sfruttare l'ossatura del sistema messo a punto nel periodo precedente, con le paraste che servivano da appoggio agli archi traversi (Fig. 2); i nuovi archi trasversali della navatelle laterali, tuttavia, pur utilizzando lo stesso livello di imposta, vengono costruiti (o parzialmente ricostruiti) ad un'altezza inferiore rispetto a quella prevista nel progetto originale del Periodo I. Con ogni probabilità vengono riutilizzate solamente le due arcate di partizione interna fra le navate: su queste vanno ad impostarsi le murature di partizione, i cui lacerti sono ancora ben visibili sul fronte ovest interno (Figg. 2-4, 11). Le navate laterali erano presumibilmente coperte da volte a botte in conci: oggi non ne rimane alcuna traccia, ma elementi riconducibili a questo sistema erano stati rilevati nel corso di ricognizioni effettuate agli inizi del ' $900^{46}$. Lo stato di conservazione delle strutture non permette di ricavare dati incontroverti- bili circa la tipologia di copertura della navata centrale, ma, in considerazione del sistema messo in opera negli ambienti laterali, e, presumibilmente, delle navatelle laterali, nonché delle tradizioni costruttive regionali, è assai verosimile fosse realizzato con volte a botte in conci.

Alla Fase 5 del Periodo II viene riferita la costruzione di un portico addossato alla facciata ovest (Fase 5 , Attività 26 , Figg. 10,14), che va a modificare quello del progetto originale del Periodo I. In realtà tale intervento potrebbe essere stato realizzato contestualmente a quelli descritti nella Fase 4, ma l'interruzione dei rapporti stratigrafici fra le parti intercorsa con i crolli ha suggerito di attribuirla prudentemente ad una diversa fase costruttiva. Una volta a botte di andamento nord-sud va ad impostarsi su una arcata addossata alla facciata ovest, ammorsata unicamente alle due paraste costruite nella Fase 2, Periodo I (Fig. 10), e su una arcata costruita a filo delle torri laterali ed impostata sulle paraste, parzialmente smontate e risistemate, già definite nel Periodo I (Figg. 2, 10, 14-15). Lo pseudo-protiro del portale centrale viene smontato per adattarsi alla nuova altezza della volta, più bassa rispetto a quella prevista nel progetto del Periodo I; la volta va anche ad obliterare in parte le due grandi finestre del fronte ovest (Figg. 9, 20). Il crollo delle porzioni sommitali non consente di comprendere appieno la configurazione del fronte ovest in questo Periodo II, ed in particolare come fosse organizzato il raccordo fra il nuovo portico e gli avancorpi.

E' dunque il cantiere del Periodo II che va a completata la basilica progettata nel Periodo I andando ad introdurre sostanziali modifiche nell'altezza delle coperture e nei porticati esterni. Nel successivo Periodo III la basilica non sarà interessata da ulteriori e sostanziali interventi di modifica, ma entrerà nella lunga fase di abbandono che andrà a trasformare l'edificio in rudere.

Per quel che riguarda la datazione della basilica, le ipotesi formulate si appoggiano ampiamente sulla letteratura pregressa che ha preso in esame le evidenze epigrafiche così come gli elementi stilistico-formali delle varie componenti decorative; su queste basi, sembra di potere collocare la fondazione della chiesa del Periodo I nell'ambito del VI secolo (si veda infra, Periodo I, Elementi cronologici).

Una inscrizione in greco (Fig. 21) collocata nella parete esterna meridionale (US 508, Fig. 14) della struttura absidale fornisce un termine post-quem per la realizzazione delle strutture della Fase 2, Periodo I: recenti analisi hanno infatti permesso di stabilire che l'iscrizione sia stata scolpita precedentemente la posa in opera, senza necessariamente costituire un reimpiego. Viene datata in letteratura a non oltre il VII secolo, ed è con ogni probabilità 
Fig. 21. Iscrizione della parete esterna sud del corpo absidale, US 508, da sud (Foto C. Tonghini)

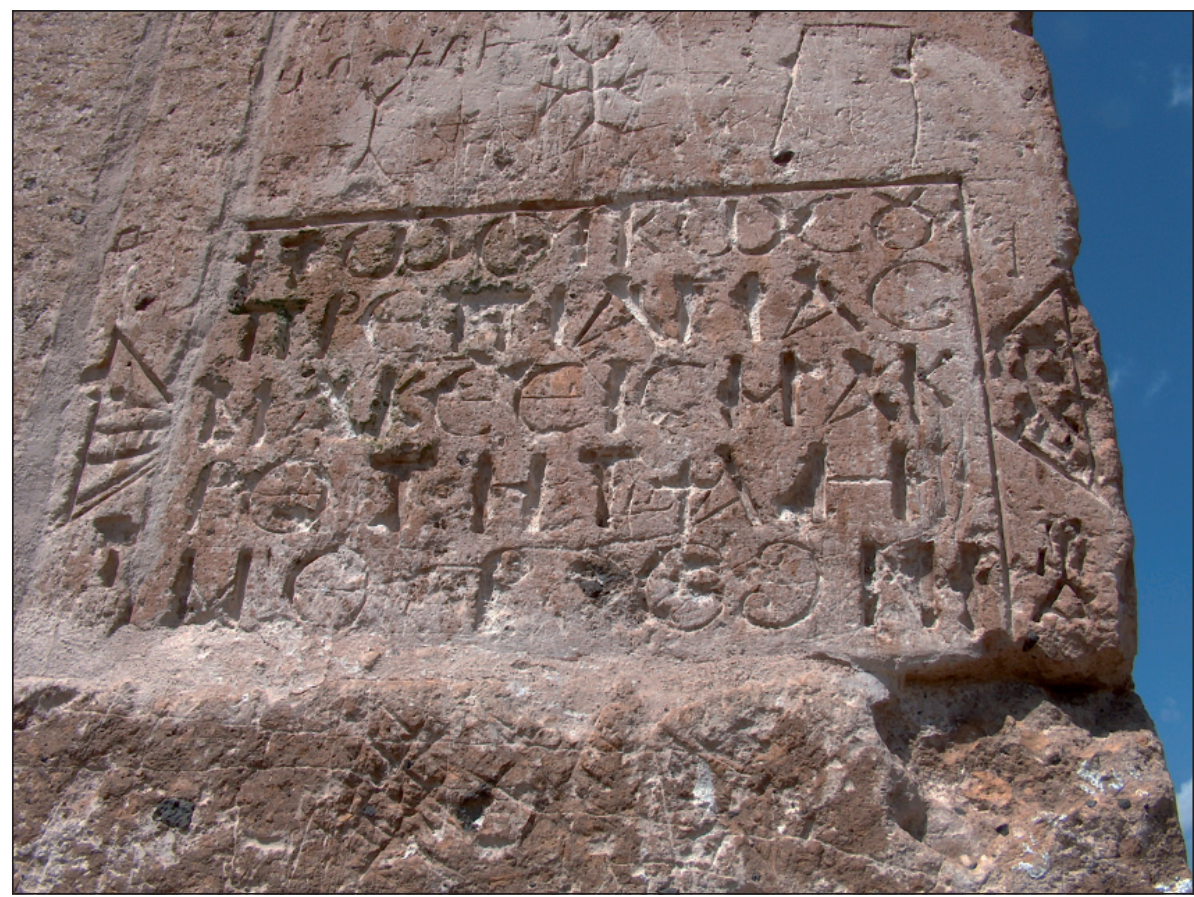

riferibile ad un orizzonte di V-VI secolo. L'analisi delle componenti decorative condotta dagli specialisti di architettura armena offre parimenti elementi di inquadramento cronologico: gli pseudo-protiri dei portali, le modanature delle aperture e i capitelli scolpiti rinviano ad un orizzonte di VI secolo.

Più complesso è invece pervenire ad un inquadramento cronologico del Periodo II, e datare l'interruzione del cantiere del Periodo I e l'avvio di quello del Periodo II. In considerazione delle tecniche e della tipologia di materiale impiegati è assai probabile che i due Periodi siano abbastanza vicini dal punto di vista cronologico.

Le due iscrizioni incise una sulla parete ovest dell'abside interna (US 411, Fig. 3) e l'altra sulla parete esterna sud (US 179, Figg. 16-17) potrebbero essere state realizzate tanto nel Periodo I quanto nel Periodo II. In considerazione del fatto che il contenuto delle iscrizioni potrebbe meglio adattarsi al contesto di una chiesa ormai completata, e tenendo conto del fatto che abbiamo ipotizzato il completamento della basilica solo nel Periodo II, è possibile che il termine ante quem che le due iscrizioni vanno a definire, i secoli VII-X la prima e 1038 la seconda, possa servire ad orientare il Periodo II. Su questa base ed in attesa di nuovi dati possiamo dunque ipotizzare che la chiesa del Periodo II dovesse essere stata completata fra VII-X secolo - e forse già al VII secolo se si considera la forte analogia fra il Periodo I ed il Periodo II in termini di forme e tecniche costruttive e tipologia di materiale impiegato-, e certamente prima del 1038 (si veda infra, Periodo II, Elementi cronologici).

Anche il lungo Periodo III relativo all'abbandono della chiesa e alla sua trasformazione in rudere è difficilmente inquadrabile dal punto di vista cronologico. Potrebbe collocarsi in un ampio arco di tempo che potremmo circoscrivere fra l'ultimo riferimento al sito di Ererouk attestato nelle fonti scritte, databile al 1208-1212, e le prima segnalazioni dei resti della basilica ad opera di viaggiatori e studiosi a partire dalla metà del XIX secolo (si veda infra, Periodo III).

E' evidente che solo il proseguimento delle indagini sul campo, con il completamento dell'analisi stratigrafica delle strutture, l'apertura di sondaggi stratigrafici e l'ampliamento delle indagini a tutto il complesso potranno in futuro portare all'acquisizione di un quadro documentario più ampio e di formulare nuove ipotesi.

\section{Riferimenti bibliografici}

Per la vastissima bibliografia sulla chiesa di Ererouk, in particolare per quel che riguarda i primi studi, si rimanda all'esaustivo elenco riportato in Documenti di Architettura Armena, 9, 1977.

Alpago-Novello 1977. Adriano Alpago-Novello, «La basilica di Ererouk. Annotazioni critiche», Ererouk (Documenti di Architettura Armena, 9), 1977, pp. $16-27$

Bessac 2011. Jean-Claude Bessac, "Observations sur la construction monumentale dans le nord-ouest de la République d'Arménie ", Syria 88, 2011, pp. 379-415. 
Bessac c.s. Jean-Claude Bessac, "Observations sur la construction de la basilique d'Ererouk en République d'Armenie, Syria, in corso di stampa.

Casnati 2005. Gaiané Casnati, Le 'pietre urlanti' d'Armenia, catalogo della mostra, Venezia, 1955.

Creswell 1952. K.A.C. Creswell, «Fortification in Islam before A.D. 1250», Proceedings of the British Academy 38, 1952, pp. 89-125.

Cuneo 1988. Paolo Cuneo, Architettura Armena, Roma, 1988.

Gandolfo 1982. Francesco Gandolfo, Le basiliche armene. IV-VII secolo, Roma, 1982.

Greenwood 2004. Timothy Greenwood, «A Corpus of Early Medieval Armenia Inscriptions", Dumbarton Oaks Papers, 58, 2004, pp. 27-91.

Kouymjian 1977. Dickran K. Kouymjian, "Breve cronologia storica», Ererouk (Documenti di Architettura Armena, 9), 1977, pp. 28-29.

Maranci 2005. Christina Maranci, Report: the Church of Ererouk, 2005, non pubblicato.

Marr 1907. N. Marr, «Ereruskaja bazilika, armjanskij xram V-VI vv.» (La basilica di Ererouk, tempio armeno dei secoli V-VI), Zapiski Vostoènogo Otdelenija Russcogo Arxeologièeskogo Obšèestva, XVIII, 1907, I, San Pietroburgo, pp. XIIXIV.

Marr 1910a. N. Marr, «Ereruskaja bazilika, armjanskij xram V-VI vv. v okrestnostjax Ani» (La basilica di Ererouk, tempio armeno dei secoli V-VI nelle vicinanze di Ani), (1910), Erevan, 1968.

Marr 1910b. N. Marr, "Noviye arxeologièeskie dannyye o postrojkax tipa Ererujskoj basiliki» (Nuovi dati archeologici circa la struttura della basilica di Ererouk), Zapiski Vostoènogo Otdelenija Russcogo Arxeologièeskogo Obšèstva, XVIII, (1909), pubblicato nel 1910, San Pietroburgo, pp. 64-68.

Paboudjin 1977. Pascal Paboudjin, «La basilica di Ererouk», Ererouk (Documenti di Architettura Armena, 9), 1977, pp. 5-15 e 32-37.

Strzygowski 1918. J. Strzygowski, Die Baukunst der Armenier und Europa, Wien, 1918.

Tonghini 2012. Cristina Tonghini, Shayzar I. The fortification of the citadel, Leiden and Boston, 2012.

Thoramanian 1942-1948. T. Thoramanian, Niouter haykakan djharta rapethoutian patmoutian (Materiali per la storia della cultura armena), Erevan, vol. I: 1942, vol. II: 1948.

Voisin 2004. J.-Cl. Voisin, «Le Moyen-Orient des fortifications. Espace des échangements entre Byzantins, Arabo-musulmans et Occidentaux au Moyenâge», in N. Faucherre, J. Mesqui, N. Prouteau (a cura di) La fortification an temps des Croisades, Rennes, 2004, pp. 313-331.

Yovitchitch 2011. Cyril Yovitchitch, Forteresses du Proche-Orient, Paris, 2011.

Recibido: 5 de abril de 2012

Aceptado: 18 de julio de 2012 